\title{
Long-term acoustic monitoring of fish calling provides baseline estimates of reproductive time- lines in the May River estuary, southeastern USA
}

\author{
Agnieszka Monczak ${ }^{1, *}$, Andrea Berry ${ }^{2}$, Chris Kehrer ${ }^{3}$, Eric W. Montie ${ }^{1, *, * *}$ \\ ${ }^{1}$ Department of Natural Sciences, University of South Carolina Beaufort, One University Boulevard, Bluffton, \\ South Carolina 29909, USA \\ ${ }^{2}$ Town of Bluffton, 1261 May River Road, PO Box 386, Bluffton, South Carolina 29910, USA \\ ${ }^{3}$ Port Royal Sound Foundation, Maritime Center, 310 Okatie Highway, Okatie, South Carolina 29909, USA
}

ABSTRACT: In this study, our goal was to perform acoustic monitoring of the May River, South Carolina (USA), for a 9 mo period and estimate reproductive timelines for a community of soniferous fishes. Acoustic recorders were deployed to collect sound samples for $2 \mathrm{~min}$, every $20 \mathrm{~min}$ at 4 stations from the source to the mouth from February to November 2013. We detected the acoustic presence of 6 fish species: Atlantic croaker Micropogonias undulatus, black drum Pogonias cromis, silver perch Bairdiella chrysoura, oyster toadfish Opsanus tau, spotted seatrout Cynoscion nebulosus, and red drum Sciaenops ocellatus. Acoustic detection rates and diversity of soniferous fish were higher near the mouth and decreased towards the source, suggesting a selection of deeper water and/or more stable water quality conditions for spawning. We estimated the start and end dates of the spawning season and calculated the total hours of chorusing for silver perch, oyster toadfish, spotted seatrout, and red drum. Each species followed a specific seasonal and daily pattern of calling, and we observed synchrony of these calling patterns among stations. For silver perch, oyster toadfish, black drum, and spotted seatrout, a negative temperature anomaly correlated with decreased calling intensity, while a positive anomaly increased sound production. For oyster toadfish and spotted seatrout, the lunar phase significantly influenced calling. These data serve as a foundation for future studies that are investigating how climate variability may affect seasonal spawning timelines and year class strength of fish populations using passive acoustic monitoring.

\footnotetext{
* These authors contributed equally to this work

${ }^{* *}$ Corresponding author: emontie@uscb.edu
}

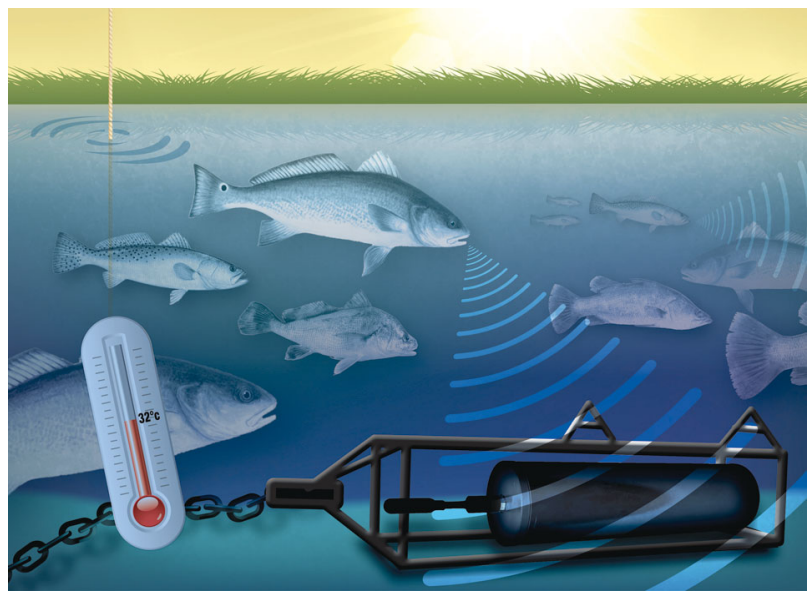

Long-term acoustic recorders (black instrument in figure) can be used to estimate spawning timelines and rhythms by detecting fish calls associated with courtship.

Design by Tim Devine, USCB Graphics Manager

KEY WORDS: Fish sound production · Spawning · Estuarine soundscapes · Silver perch · Oyster toadfish · Black drum · Spotted seatrout $\cdot$ Red drum · Fish acoustics

\section{INTRODUCTION}

In estuarine ecosystems of the southeastern USA, significant contributors to the marine soundscape are the sounds produced by fish. In the family Batrachoididae, 1 sound-producing fish native to estuaries is the oyster toadfish Opsanus tau (Gray \& Winn 1961, Fine 1978, Maruska \& Mensinger 2009, Montie et al.

(C) The authors 2017. Open Access under Creative Commons by Attribution Licence. Use, distribution and reproduction are unrestricted. Authors and original publication must be credited. 
2015). In the family Sciaenidae, sound-producing fishes include Atlantic croaker Micropogonias undulatus, silver perch Bairdiella chrysoura, black drum Pogonias cromis, spotted seatrout Cynoscion nebulosus, weakfish C. regalis, red drum Sciaenops ocellatus, spot Leiostomus xanthurus, and southern kingfish Menticirrhus americanus (Luczkovich et al. 1999, 2008, Sprague 2000, Ramcharitar et al. 2006, Gannon \& Taylor 2007, Lowerre-Barbieri et al. 2008, Walters et al. 2009, Tellechea et al. 2011, Montie et al. 2015). Sound production in these fishes typically involves rapid movement of the sonic muscle surrounding the swim bladder. The resulting calls are species-specific due to anatomical differences in swim bladder and sonic muscle morphology as well as neural programming; therefore, call types can be used for species identification (Winn 1964, Ramcharitar et al. 2006).

Sound production in fish species has been associated mainly with courtship behavior and reproduction (e.g. Saucier \& Baltz 1993, Mann \& Lobel 1995, Luczkovich et al. 2008, Walters et al. 2009, Mann et al. 2010, Montie et al. 2016, 2017). Studies have recorded underwater sounds during spawning seasons and have shown that patterns of peak calling coincide with patterns of reproductive senescence (i.e. gonadosomatic indices, sperm motility, and plasma androgen levels; Connaughton \& Taylor 1995). Other wild studies have simultaneously collected acoustic recordings and plankton tows, and these data have shown that fish calling and spawning are tightly associated (Mok \& Gilmore 1983, Saucier \& Baltz 1993, Luczkovich et al. 1999, Aalbers \& Drawbridge 2008, Lowerre-Barbieri et al. 2008). For example, the timing and amount of calling in wild weakfish were positively correlated with the timing and numbers of sciaenid eggs collected (Luczkovich et al. 1999). Similar findings have been observed in captive studies (Guest \& Lasswell 1978, Connaughton \& Taylor 1996, Lowerre-Barbieri et al. 2008, Montie et al. 2016, 2017). In weakfish held in laboratory tanks, courtship behavior, male calling, and spawning were correlated (Connaughton \& Taylor 1996). In a quantitative study with captive red drum, findings revealed that spawning was more productive when the amount of calling increased; more eggs were collected when calls were longer in duration and contained more pulses (Montie et al. 2016). In a similar study with captive spotted seatrout, spawning was more likely to occur when male fish called more frequently; a positive relationship was found between sound pressure levels in tanks and the number of eggs collected (Montie et al. 2017). These findings indicate that acoustic metrics can accurately predict spawning potential for some soniferous fishes and that deployment of long-term acoustic recorders can estimate reproductive timelines.

This knowledge is important because it could provide a model system to detect phenological shifts in reproduction associated with climate change. In fact, there is now clear evidence that climate change has affected Earth's ecosystems by affecting the timing of reproduction, which for many animals, is finely tuned to specific seasons and environmental temperatures (Walther et al. 2002, Hoegh-Guldberg \& Bruno 2010). In marine ecosystems, it can be challenging to determine when reproductive seasons begin and end because of the logistical challenges of visually observing reproduction underwater. It is time consuming to sample and process the water column for identification of eggs and larvae at the necessary time scales. In addition, plankton sampling and quantification of eggs and larvae (i.e. by hatching or molecular techniques) does not provide exact information about when and where spawning occurred, since the number of eggs/larvae collected in the field is likely affected by predator activity and water currents (Holt et al. 1985, Brown et al. 2005, Goffredi et al. 2006, Mortensen et al. 2015). To our advantage and as discussed previously, many fish produce acoustic signals as part of their courtship behavior. We can capitalize on detecting these sounds to eavesdrop on species-specific spawning seasons. In fact, this approach has been used to detect earlier choruses and spawning in amphibians (Beebee 1995, Loman 2016) and earlier breeding or first singing of birds as a result of warmer springs (Crick et al. 1997, Crick \& Sparks 1999, Brown et al. 1999, Dunn \& Winkler 1999).

In a past study in the May River, South Carolina, we defined the general seasonal patterns of sound production for black drum, silver perch, oyster toadfish, spotted seatrout, and red drum (Montie et al. 2015). Seasonally, silver perch, oyster toadfish, and black drum began calling in early spring and ended in May; sound production of spotted seatrout began in late winter (February) and ended in early fall (end of September), and the majority of red drum sound production occurred in August and September (Montie et al. 2015). These sound production timelines were consistent with the spawning timelines observed in other studies along the Southeast Atlantic coast and the Gulf of Mexico, which were based upon on the detection of courtship sounds, gonad indices, the presence of eggs and larvae in the water column, and/or appearance of young of the year (YOY) (Dobrin 1947, Tavolga 1960, Fish \& Mowbray 1970, 
Overstreet 1983, Fine et al. 1984, Beckman et al. 1988, Brown-Peterson et al. 1988, 2002, McMichael \& Peters 1989, Murphy \& Taylor 1990, Saucier \& Baltz 1993, Ross et al. 1995, Sprague 2000, Brown-Peterson \& Warren 2002, Nieland et al. 2002, Roumillat \& Brouwer 2004, Ramcharitar at al. 2006, Locascio \& Mann 2008, Luczkovich et al. 2008, Locascio \& Mann 2011, Wall et al. 2013, Montie et al. 2015). For example, spotted seatrout have an extended spawning season from April to September along the Gulf of Mexico and South Atlantic coasts, with YOY appearance occurring throughout the summer (Overstreet 1983, Brown-Peterson et al. 1988, 2002, McMichael \& Peters 1989, Saucier \& Baltz 1993, Brown-Peterson \& Warren 2002, Nieland et al. 2002, Roumillat \& Brouwer 2004). Red drum have a shortened spawning timeframe, which occurs from mid-August through October along the Atlantic coast and the Gulf of Mexico, with sexually mature adults, larvae, and YOY (<150 mm) occurring only in the fall (Murphy \& Taylor 1990, Ross et al. 1995).

Our overall goal in the present study was to provide baseline information on reproductive timelines for a community of soniferous fishes in the May River, South Carolina, predicted by the detection of fish courtship sounds using an array of long-term acoustic recorders. The specific objectives were to: (1) identify and characterize the power spectrum of fish sounds and choruses that were significant contributors to the estuarine soundscape; (2) describe the spatial differences of sound production and changes in species distribution from the source to the mouth of this large tidal river; (3) estimate spawning start and end dates, temperature ranges of spawning, duration of the reproductive season, and spawning frequency based on the detection of chorusing aggregations; and (4) determine how certain factors (i.e. location, month, day length, water temperature anomaly, lunar phase, and tidal range) influence calling and chorusing. These data will provide a foundation for future studies that are investigating how climate change may affect estuarine soundscapes and seasonal reproduction of soniferous fishes.

\section{MATERIALS AND METHODS}

\section{Study area}

We performed long-term acoustic monitoring of the May River (32¹2'49"N, 8052' 23"W), South Carolina, a large subtidal river estuary that is approximately $22 \mathrm{~km}$ long and $0.01 \mathrm{~km}$ wide near the source

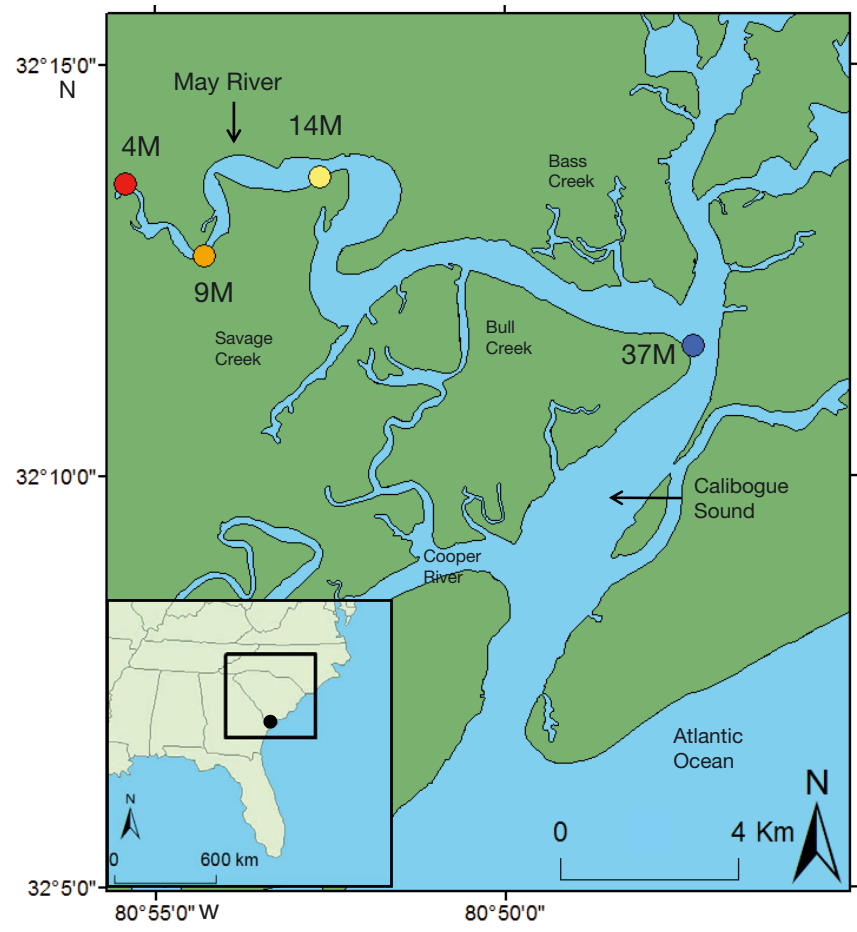

Fig. 1. Locations of Stations $4 \mathrm{M}, 9 \mathrm{M}, 14 \mathrm{M}$, and $37 \mathrm{M}$ that were acoustically monitored from 23 February to 23 November 2013. Stn $4 \mathrm{M}$ (red circle) was located near the source and Stn 37M (blue circle) was located at the mouth of the tidal river. Inset: May River, South Carolina (black circle), showing the approximate location of this large tidal river in reference to the US east coast

and $1 \mathrm{~km}$ wide at the mouth (Fig. 1). The water depth ranges from $\sim 3$ to $7 \mathrm{~m}$ near the source and from $\sim 4$ to $18 \mathrm{~m}$ near the mouth. There are smaller subtidal creeks (i.e. Savage, Bull, and Bass Creeks) and numerous intertidal creeks along the river. Bordering the river and creeks are intermittent oyster rubble and live oyster reefs and vast areas of salt marsh composed of smooth cord grass Spartina alterniflora. This estuary is strongly influenced by $\sim 2.5$ to $3 \mathrm{~m}$ semi-diurnal tides. The salinity variability is high, ranging from $21.12 \pm 7.76 \%$ o $( \pm \mathrm{SD})$ near the source to $29.23 \pm 2.56 \%$ near the mouth. Salinity values vary depending upon the tidal cycle and the degree of stormwater runoff; however, the greatest variability is near the source because of the low volume of water.

\section{Acoustic and environmental data collection}

We deployed autonomous, acoustic recorders (DSG-Ocean, Loggerhead Instruments) to monitor the estuarine soundscape at 4 locations (i.e. Stations $4 \mathrm{M}, 9 \mathrm{M}, 14 \mathrm{M}$, and $37 \mathrm{M}$ ) based upon previous work 
(Fig. 1; Montie et al. 2015). In that study, fish sound production was investigated by collecting monthly, short-term acoustic recordings at 27 stations throughout the May River from January to December 2012. Using these data, we deployed an acoustic recorder at Stn $4 \mathrm{M}$ because this location exhibited minimal calling; we deployed acoustic recorders at Stns 9M, $14 \mathrm{M}$, and $37 \mathrm{M}$ because data revealed that those locations contained large chorusing aggregations of silver perch, spotted seatrout, and/or red drum.

We mounted DSG-Ocean recorders in custom built instrument frames (Mooring Systems) with attached water level and temperature loggers (HOBO 100Foot Depth Water Level Data Logger U20-001-02-Ti and HOBO Water Temperature Pro v2 U22-001, Onset Computer; Fig. 2). Water depth measurements were scheduled to record every $10 \mathrm{~min}$. These measurements were determined from bottom depth pressure and atmospheric pressure readings (HOBO 100-Foot Barometric Pressure Level Data Logger U20-001-02-Ti, Onset Computer) using formulas provided by Onset Computer. The factory-calibrated range for the $\mathrm{HOBO}$ depth water level logger is between 69 and $400 \mathrm{kPa}$, which was within our bottom pressure ranges of $100-180 \mathrm{kPa}$. The maximum error for the absolute pressure sensor is $\pm 1.2 \mathrm{kPa}$. Water temperature loggers were scheduled every hour. These HOBO loggers can measure temperatures between -40 and $+50^{\circ} \mathrm{C}$ in water with $\pm 0.21^{\circ} \mathrm{C}$ accuracy. Both water depth and temperature loggers were calibrated by the factory. The HOBO loggers

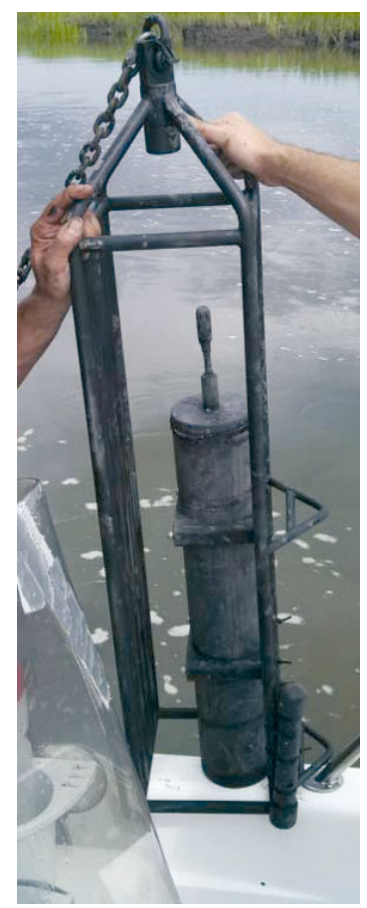
were placed in PVC housing and attached to the inside of the instrument frame with zip ties. The instrument frame, DSGOcean, and PVC logger housings were spraypainted with antifouling paint (Trilux 33, West Marine). The instrument frames were then deployed on the bottom approximately $10 \mathrm{~m}$ from

Fig. 2. Long-term acoustic recorders (DSG-Ocean) were deployed on the bottom of the May River. DSG-Ocean recorders were mounted in frames to minimize noise artifacts and impacts on the instruments the shoreline. This deployment method was accomplished by attaching a $7 \mathrm{~m}$ galvanized chain to the instrument frame. The chain was then attached to a line, which stretched along the river bottom to an auger that was inserted into the sediment along the side of the marsh. This method allowed deployment and retrieval of instruments without the need for scuba diving. In addition, this setup minimized moving parts and noise artifacts and protected the recorder and loggers.

The DSG-Ocean recorder is equipped with a High Tech hydrophone (i.e. sensitivity of $-185 \mathrm{dBV} \mu \mathrm{Pa}^{-1}$ ) with a flat frequency response between $\sim 0.1$ and $30 \mathrm{kHz}$. The system is calibrated by the manufacturer with a $0.1 \mathrm{~V}$ (peak) frequency sweep from $2-100 \mathrm{kHz}$, and it is powered by $24 \mathrm{D}$-cell alkaline batteries housed in a cylindrical PVC tube (i.e. $0.65 \mathrm{~cm}$ length, $11.5 \mathrm{~cm}$ diameter). In this study, the DSG-Ocean units were scheduled to record the soundscape for 2 min every 20 min Eastern Standard Time (EST) at a sampling rate of $80 \mathrm{kHz}$ from 23 February to 23 November 2013 over 3 deployments. Acoustic recordings were saved as DSG files on a 128 GB SD card. DSG files were downloaded and batch converted into wav files using DSG2wav@ (Loggerhead Instruments). HOBO logger data were downloaded using HOBOware®Pro software (Onset Computer). DSG-Ocean recorders were then outfitted with new batteries and reassembled in instrument frames with HOBO loggers for redeployment following methods previously described. Additional environmental parameters (i.e. salinity and $\mathrm{pH}$ ) were recorded with a YSI 556 Handheld Multiparameter Instrument (YSI/Xylem) approximately once a month at the acoustic stations. For each parameter, means, standard deviations, minimum, and maximum values are reported. Salinity and $\mathrm{pH}$ were not included in statistical analysis because these parameters were not recorded continuously.

\section{Acoustic analysis}

During this study, we collected a total of 70272 acoustic files. Each 2 min wav file was manually reviewed using Adobe Audition CS5.5 software (Adobe Systems). Spectrograms were visualized using a spectral resolution of 2048 (i.e. the number of vertical bands used to draw frequencies in the Adobe Audition spectrogram) and a $10 \mathrm{~s}$ time window (i.e. zooming in the Adobe Audition spectrogram to show $10 \mathrm{~s}$ at a time). Calls of black drum, oyster toadfish, silver perch, spotted seatrout, red drum, and Atlantic 
croaker were detected during the analysis. These calls were identified by comparing acoustic recordings to spectrograms published in previous studies (Tavolga 1958, Luczkovich et al. 1999, Sprague 2000, Rountree et al. 2006, Montie et al. 2015, 2016, 2017). For each 2 min wav file, an observer scored the file based upon the intensity of calling for each fish species. The calling intensity score was based on 4 categories (i.e. $0=$ no calls; $1=1$ call; $2=$ multiple calls; 3 = overlapping calls or chorus) following similar methods described previously (Luczkovich et al. 2008). An observer also recorded other sounds and noises originating from boats, rain, bottlenose dolphins Tursiops truncatus (i.e. echolocation, whistles, and burst pulse sounds), and unknown sounds. These data were entered into a standardized spreadsheet in Microsoft Excel 2010. For oyster toadfish, we only categorized the 'boat whistle' call, which has been associated with courtship, and did not quantify 'grunt' calls, which have been associated with nonadvertisement vocalizations (Fine \& Thorson 2008, Maruska \& Mensinger 2009). For spotted seatrout, we grouped 'grunts,' 'drums,' and 'staccato' calls during analysis (Mok \& Gilmore 1983, Montie et al. 2015, 2017). From these data, we summed calling intensity scores per night (12:00 to 11:40 $\mathrm{h}$ the next day) for black drum, silver perch, oyster toadfish, spotted seatrout, and red drum.

We determined the frequency range of each species-specific call or chorus by performing an average power spectral density (PSD) between 50 and $10000 \mathrm{~Hz}$ using a Fast Fourier Transform with 80000 samples, which corresponded to a frequency resolution of $1 \mathrm{~Hz}$. To construct average PSDs, we used between 50 and 100 sound clips of the same length for each call or chorus. For each 2 min wav file and each fish species, we attempted to determine the root mean square $(\mathrm{rms})$ received sound pressure level (SPL) by focusing on fish-specific frequency bands (i.e. black drum $70-90 \mathrm{~Hz}$; silver perch $1000-$ $1280 \mathrm{~Hz}$; oyster toadfish $190-200 \mathrm{~Hz}$; spotted seatrout $200-270 \mathrm{~Hz}_{\text {; }}$ and red drum $120-160 \mathrm{~Hz}$ ) that were derived from the comparisons of PSDs. The equations for received SPL determination followed Merchant et al. (2015):

$$
\begin{gathered}
S=h+g+20 \log _{10}\left(1 / V_{\text {adc }}\right) \\
b=20 \log _{10}\left\{\operatorname{sqrt}\left[\operatorname{mean}\left(y^{2}\right)\right]\right\} \\
a=b-S
\end{gathered}
$$

where $a=$ calibrated sound level in $\mathrm{dB}$ re $1 \mu \mathrm{Pa}$; $b=$ uncorrected signal; $S=$ correction factor; $h=$ hydrophone sensitivity (i.e. $-185 \mathrm{dBV} \mu \mathrm{Pa}^{-1}$ ); $g=$
DSG gain (i.e. $20 \mathrm{~dB}$ ); $V_{\mathrm{adc}}=$ analog-to-digital conversion (i.e. 1 volt); $y=$ signal. A 5-point moving average was applied to SPL data to smooth and reduce variability from boat sounds.

\section{Statistical analysis}

Statistical analyses were performed using SPSS Statistics 24 (IBM). Spearman's correlation tested the relationship between the maximum calling intensity score and the maximum rms-received SPL each night for each fish species at each station. To examine the general spatial differences in fish calling and diversity, we determined the number of acoustic files with calls or chorusing for each species at each station. We determined the dates when calling and chorusing began and ended as well as temperature ranges, daylight ranges, and the frequency of calling or chorusing. In addition, we estimated the total number of hours in which chorusing occurred over the calling season. We assumed that the chorus continued throughout the 18 min interval.

To investigate the temporal patterns of calling, we plotted the nightly summed intensity score and corresponding water temperature, hours of daylight, and lunar cycle versus the date. To examine temporal synchrony of calling among the different stations sampled, we performed a series of Pearson correlation coefficient tests between the stations (i.e. $4 \mathrm{M}$ vs. $9 \mathrm{M} ; 4 \mathrm{M}$ vs. $14 \mathrm{M} ; 4 \mathrm{M}$ vs. $37 \mathrm{M} ; 9 \mathrm{M}$ vs. $37 \mathrm{M}$; and $14 \mathrm{M}$ vs. $37 \mathrm{M}$ ) using the nightly summed calling intensity scores as variables. We then calculated the distances between stations to determine if calling patterns at stations closer to each other had higher correlations than stations further apart. To investigate and compare the daily patterns of sound production for each fish species, we calculated the mean calling intensity score and the species-specific rms SPL for each time period.

We used a general linear model (GLM) to test which variables (i.e. station, month, day length, temperature anomaly, lunar phase, and tidal range) significantly influenced the nightly summed intensity score for each species. We examined the histogram and skewness of the residuals. The skewness for each species test was between -0.5 and 0.5 , which indicated that the data were close to a normal distribution (Ghasemi \& Zahediasl 2012, Kim 2013). The temperature anomaly was calculated by first performing a $30 \mathrm{~d}$ moving average of the water temperature data and then subtracting the observed temperature data. A positive anomaly indicated that the observed temper- 
ature was warmer than the $30 \mathrm{~d}$ moving average, while a negative anomaly indicated that the observed temperature was cooler than the $30 \mathrm{~d}$ moving average. We used 4 categories to differentiate the lunar cycle: new moon (lunar days 27-4), first quarter (lunar days 5-11), full moon (lunar days 12-19), and third quarter (lunar days 20-26) (Eggleston et al. 1998). If categorical variables (i.e. station, month, and lunar phase) significantly influenced calling intensity, we performed additional tests to determine whether group means were significantly different. We used Tukey's honestly significant difference (HSD) test if assumptions were not violated; otherwise, we used Dunnett's test. We did not perform GLM analysis for black drum and red drum since calling was only detected at 1 and 2 stations, respectively. In addition, we performed separate linear regressions that tested the relationship between temperature anomalies and calling intensity for each species combining data from all stations.

\section{RESULTS}

\section{Fish sounds in the May River}

Through manual analyses of the acoustic files collected between 23 February and 23 November 2013, we detected the acoustic presence of 6 fish species: Atlantic croaker, black drum, silver perch, oyster toadfish, spotted seatrout, and red drum (see Fig. S1 in the Supplement at www.int-res.com/articles/suppl/ m581p001_supp.pdf). Silver perch and spotted seatrout often formed chorusing aggregations, which were detected in the $2 \mathrm{~min}$ recordings as overlapping calls (Fig. S2). In some cases, chorusing was observed in oyster toadfish and red drum (Fig. S2). Atlantic croaker calls were detected infrequently (i.e. in 130 files; $0.18 \%$ of 70272 wav files reviewed). These detections occurred between August and November at all stations (i.e. $4 \mathrm{M}=10$ files; $9 \mathrm{M}=41$ files; $14 \mathrm{M}=$ 58 files; and $37 \mathrm{M}=21$ files). Further analysis of this species was not performed. Spatially, the highest species diversity was detected at the mouth of the May River (i.e. Stn $37 M_{i} 5$ fish species), where we heard black drum, oyster toadfish, silver perch, spotted seatrout, and red drum; the lowest diversity was observed near the source (i.e. Stn $4 \mathrm{M}_{i} 2$ fish species) with only oyster toadfish and silver perch calls detected (Fig. 3A). The highest number of files with fish calls present was observed at Stn $37 \mathrm{M}$ (i.e. 10762; $61 \%$ of the total files analyzed) and the lowest at Stn $4 \mathrm{M}$ (i.e. $2912 ; 17 \%$ of the total files; Fig. 3A).
Chorusing aggregations of silver perch were found at all stations, with fewer detections near the source (i.e. $4 \mathrm{M}$ ) and most detections at the mouth (i.e. $37 \mathrm{M}$; Fig. 3B). Oyster toadfish calling was so abundant at Stn $14 \mathrm{M}$ that many recordings indicated synchronous calling episodes (i.e. 2216 wav files; $13 \%$ of the total detections of oyster toadfish). Spotted seatrout chorusing aggregations were detected at Stns 9M, 14M, and $37 \mathrm{M}$, while red drum chorusing aggregations were only detected at the mouth of the May River (i.e. 37M). The source of the May River experienced intense fluctuations in environmental parameters (salinity, temperature, and $\mathrm{pH}$ ), while the mouth of the river experienced less variability in salinity (Table 1). These water quality patterns may explain
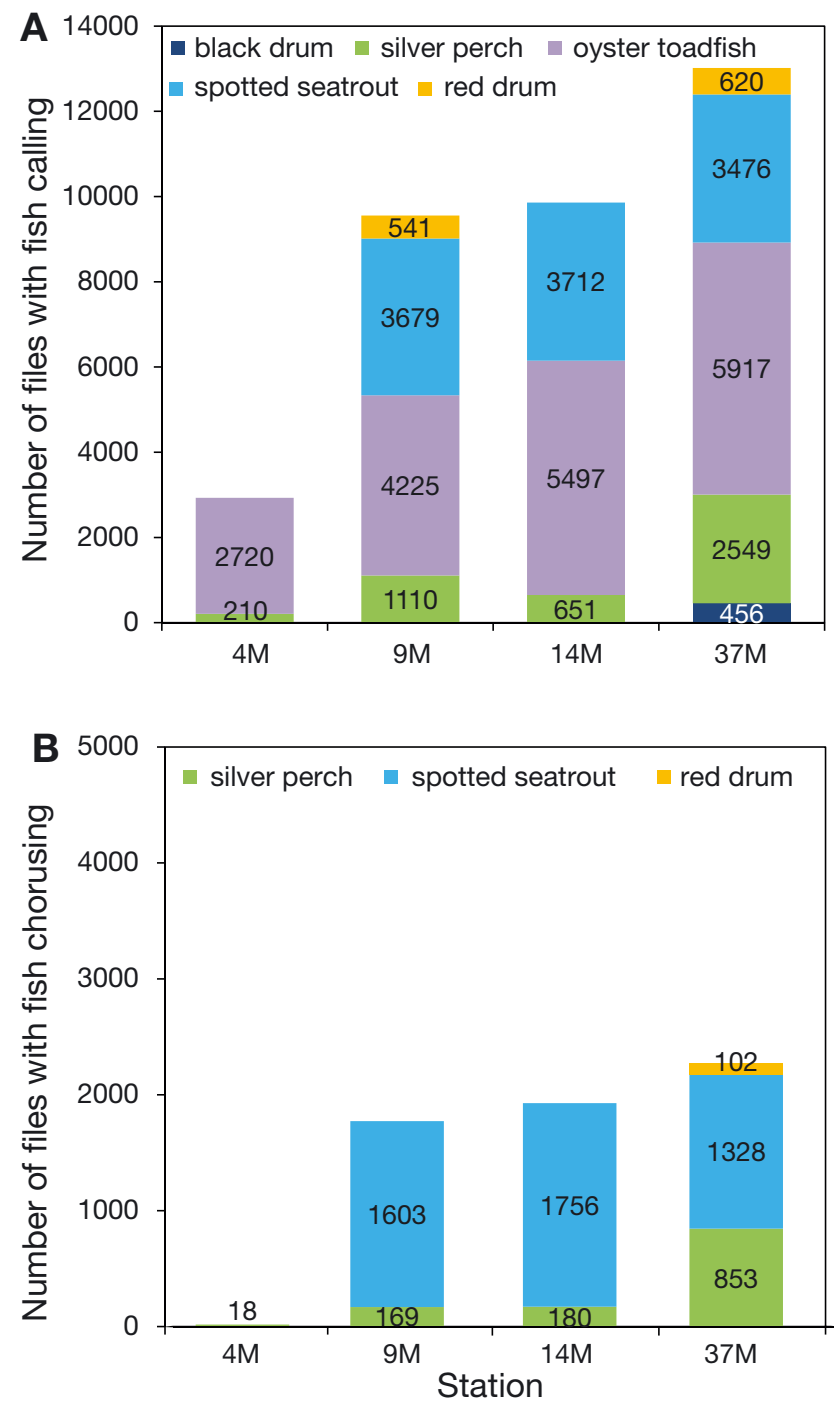

Fig. 3. Number of acoustic files in which (A) calling and (B) chorusing were detected for fish that dominated the May River soundscape. Choruses of oyster toadfish Opsanus tau at Stn 14M were not included in panel B 
Table 1. Comparison of water quality parameters among stations in the May River, South Carolina

\begin{tabular}{|c|c|c|c|c|c|c|c|c|c|}
\hline \multirow[t]{2}{*}{ Stn } & \multicolumn{3}{|c|}{ Salinity $(\%)$} & \multicolumn{3}{|c|}{ Temperature $\left({ }^{\circ} \mathrm{C}\right)$} & \multicolumn{3}{|c|}{$\mathrm{pH}$} \\
\hline & Mean \pm SD & Max. & Min. & Mean \pm SD & Max. & Min. & Mean $\pm \mathrm{SD}$ & Max. & Min \\
\hline $4 \mathrm{M}$ & $21.12 \pm 7.76$ & 31.25 & 4.88 & $23.79 \pm 5.99$ & 34.36 & 7.43 & $8.35 \pm 3.17$ & 11.12 & 6.84 \\
\hline $9 \mathrm{M}$ & $24.92 \pm 5.30$ & 32.19 & 15.89 & $23.91 \pm 5.93$ & 33.34 & 9.10 & $8.56 \pm 2.36$ & 11.08 & 7.13 \\
\hline $14 \mathrm{M}$ & $26.86 \pm 2.30$ & 32.40 & 22.20 & $23.89 \pm 5.66$ & 32.77 & 10.75 & $8.83 \pm 2.31$ & 11.45 & 6.00 \\
\hline $37 \mathrm{M}$ & $29.23 \pm 2.56$ & 33.92 & 25.90 & $23.47 \pm 4.99$ & 32.77 & 10.86 & $9.08 \pm 3.07$ & 11.57 & 7.51 \\
\hline
\end{tabular}

the higher species diversity and more abundant calling detected at the mouth of the May River as compared to the source.

Average PSDs revealed unique acoustic signatures for each fish species (Fig. 4; Fig. S3). Using species-
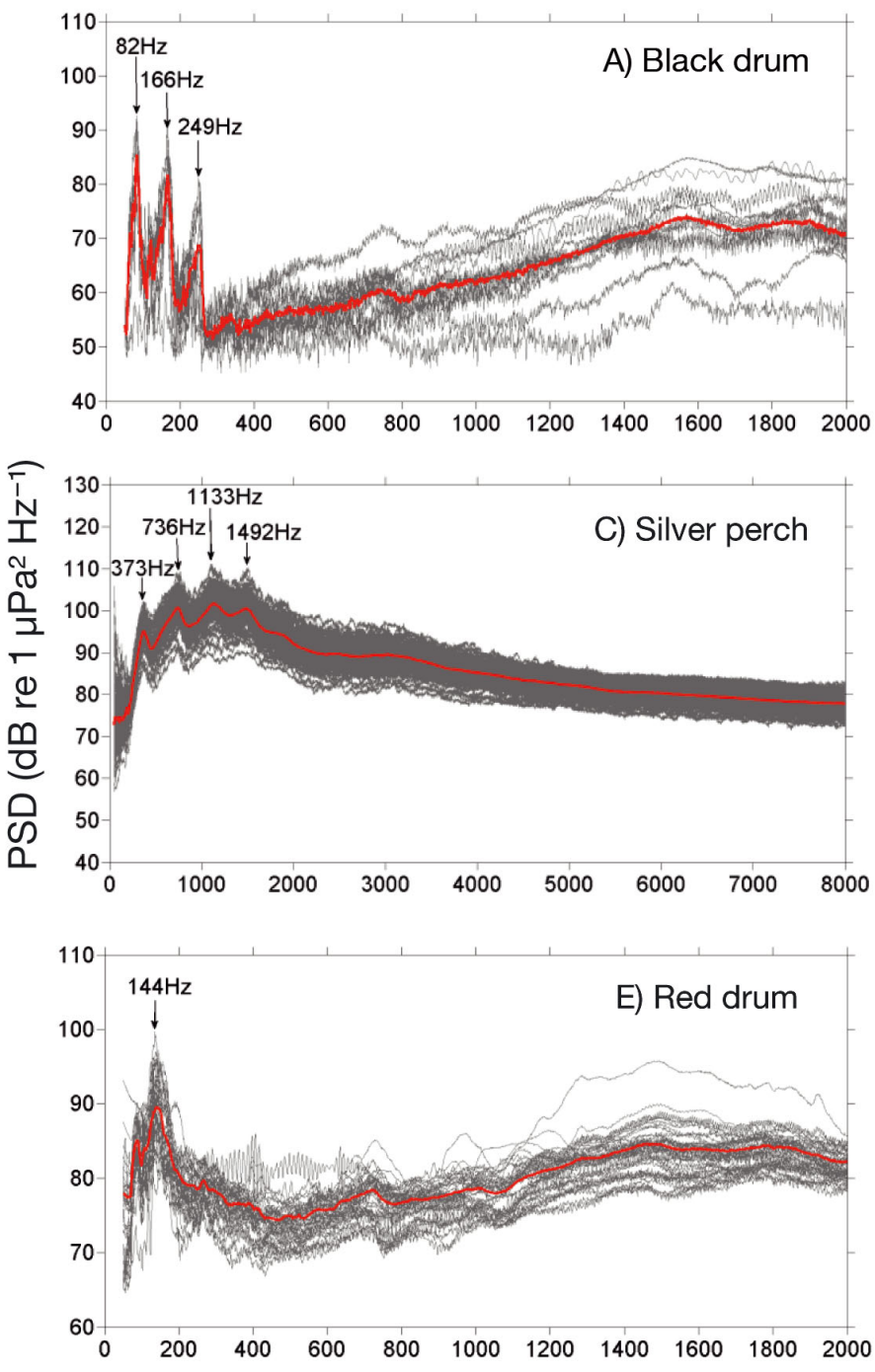

specific frequency bandwidths derived from the comparisons of the average PSDs, we correlated the maximum calling intensity scores and the maximum rms SPL night ${ }^{-1}$ for each fish species (Table 2). We observed significant positive correlations between
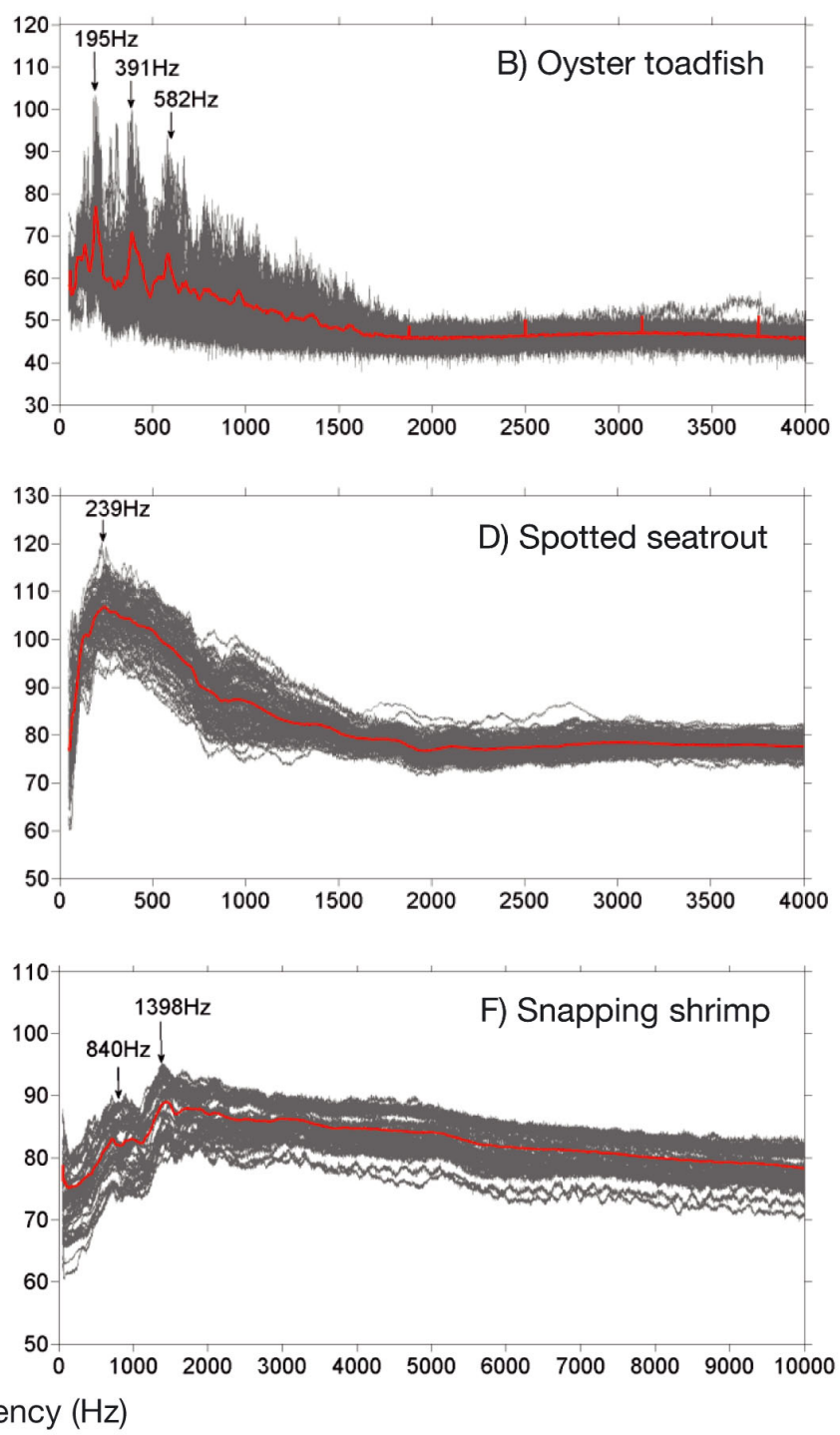

Fig. 4. Individual power spectral densities (PSDs) and mean PSDs (red lines) for (A) black drum Pogonias cromis, (B) oyster toadfish Opsanus tau, (C) silver perch Bairdiella chrysoura, (D) spotted seatrout Cynoscion nebulosus, (E) red drum Sciaenops ocellatus, and (F) snapping shrimp (genera Alpheus and Synalpheus) sounds recorded in the May River. Arrows and corresponding numbers indicate dominant frequency peaks of acoustic communication 
intensity score and species-specific rms SPL for silver perch and oyster toadfish at Stn 37M; spotted seatrout at Stns 9M, 14M, 37M; and red drum at Stns 9M

Table 2. Spearman's rho correlations $\left(\mathrm{r}_{\mathrm{S}}\right)$ and $\mathrm{p}$-values comparing maximum calling intensity and maximum speciesspecific root mean square sound pressure levels per night; nd: calling was not detected. Values in bold are significant at $\mathrm{p}<0.05$

\begin{tabular}{|lccc|}
\hline Species & Station & $\mathrm{r}_{\mathrm{S}}$ & $\mathrm{p}$ \\
\hline Black drum Pogonias cromis & $4 \mathrm{M}$ & $\mathrm{nd}$ & $\mathrm{nd}$ \\
& $9 \mathrm{M}$ & $\mathrm{nd}$ & $\mathrm{nd}$ \\
& $14 \mathrm{M}$ & $\mathrm{nd}$ & $\mathrm{nd}$ \\
& $37 \mathrm{M}$ & -0.05 & 0.43 \\
Silver perch Bairdiella & $4 \mathrm{M}$ & -0.07 & 0.30 \\
chrysoura & $9 \mathrm{M}$ & -0.10 & 0.13 \\
& $14 \mathrm{M}$ & -0.12 & 0.10 \\
Oyster toadfish Opsanus tau & $37 \mathrm{M}$ & $\mathbf{0 . 5 0}$ & $<\mathbf{0 . 0 1}$ \\
& $4 \mathrm{M}$ & 0.12 & 0.10 \\
& $9 \mathrm{M}$ & -0.04 & 0.53 \\
& $14 \mathrm{M}$ & 0.11 & 0.08 \\
Spotted seatrout Cynoscion & $37 \mathrm{M}$ & $\mathbf{0 . 3 3}$ & $<\mathbf{0 . 0 1}$ \\
nebulosus & $4 \mathrm{M}$ & $\mathrm{nd}$ & $\mathrm{nd}$ \\
& $9 \mathrm{M}$ & $\mathbf{0 . 8 7}$ & $\mathbf{< 0 . 0 1}$ \\
& $14 \mathrm{M}$ & $\mathbf{0 . 7 9}$ & $<\mathbf{0 . 0 1}$ \\
Red drum Sciaenops & $37 \mathrm{M}$ & $\mathbf{0 . 8 5}$ & $<\mathbf{0 . 0 1}$ \\
ocellatus & $4 \mathrm{M}$ & $\mathrm{nd}$ & $\mathrm{nd}$ \\
& $9 \mathrm{M}$ & $\mathbf{0 . 2 5}$ & $<\mathbf{0 . 0 1}$ \\
& $14 \mathrm{M}$ & $\mathrm{nd}$ & $\mathrm{nd}$ \\
& $37 \mathrm{M}$ & $\mathbf{0 . 1 7}$ & $\mathbf{0 . 0 1}$ \\
\hline
\end{tabular}

and 37M (Table 2). We found that the patterns of calling intensity scores were similar to the patterns of the maximum rms SPL night ${ }^{-1}$ for spotted seatrout at Stns 9M, 14M, and $37 \mathrm{M}$ and for silver perch at Stn 37M (Fig. S4).

\section{Temporal patterns of sound production}

Long-term acoustic monitoring allowed us to determine the dates when calling began and ended for 5 fish species (Table 3). Similar to other studies, we detected seasonal patterns of calling for black drum, silver perch, oyster toadfish, spotted seatrout, and red drum (Fig. 5). In the spring, as the water temperature and daylight hours increased, calling by silver perch, oyster toadfish, black drum, and spotted seatrout was more prevalent; these acoustic signals overlapped in space and time. As summer approached and water temperature rose and daylight lengthened, black drum and silver perch calling ended, oyster toadfish called less frequently, and spotted seatrout became the dominant sound producer. As fall approached, and the water temperature declined and daylight hours shortened, spotted seatrout calling began to wane, and red drum began calling. Red drum sound production peaked in the fall.

Table 3. Seasonal timelines, temperatures, hours of daylight, and frequency in which calling was detected for each fish species at each station. \% of days calling: the number of days calling divided by the number of days monitored multiplied by $100 ;$ temperature and daylight ranges are given as minimum to maximum; nd: calling was not detected

\begin{tabular}{|c|c|c|c|c|c|}
\hline Species & Station & $\begin{array}{l}\text { Date range } \\
(\mathrm{mm} / \mathrm{dd} / \mathrm{yy})\end{array}$ & $\begin{array}{l}\text { Temperature } \\
\text { range }\left({ }^{\circ} \mathrm{C}\right)\end{array}$ & $\begin{array}{l}\text { Daylight } \\
\text { range }(\mathrm{h})\end{array}$ & $\begin{array}{l}\text { Number (and \%) } \\
\text { of days calling }\end{array}$ \\
\hline Black drum Pogonias cromis & $\begin{array}{c}4 \mathrm{M} \\
9 \mathrm{M} \\
14 \mathrm{M} \\
37 \mathrm{M}\end{array}$ & $\begin{array}{c}\text { nd } \\
\text { nd } \\
\text { nd } \\
03 / 15 / 13-05 / 07 / 13\end{array}$ & $\begin{array}{c}\text { nd } \\
\text { nd } \\
\text { nd } \\
13.18-24.37\end{array}$ & $\begin{array}{c}\text { nd } \\
\text { nd } \\
\text { nd } \\
11.97-13.62\end{array}$ & $\begin{array}{c}0(0) \\
0(0) \\
0(0) \\
54(22)\end{array}$ \\
\hline Silver perch Bairdiella chrysoura & $\begin{array}{c}4 \mathrm{M} \\
9 \mathrm{M} \\
14 \mathrm{M} \\
37 \mathrm{M}\end{array}$ & $\begin{array}{l}03 / 12 / 13-04 / 11 / 13 \\
03 / 07 / 13-06 / 01 / 13 \\
03 / 18 / 13-06 / 05 / 13 \\
03 / 19 / 13-06 / 26 / 13\end{array}$ & $\begin{array}{l}11.23-25.94 \\
10.23-29.72 \\
13.26-30.07 \\
13.18-29.92\end{array}$ & $\begin{array}{r}11.87-12.85 \\
11.7-14.13 \\
12.07-14.18 \\
12.07-14.25\end{array}$ & $\begin{array}{l}31(13) \\
78(32) \\
71(29) \\
91(37)\end{array}$ \\
\hline Oyster toadfish Opsanus tau & $\begin{array}{c}4 \mathrm{M} \\
9 \mathrm{M} \\
14 \mathrm{M} \\
37 \mathrm{M}\end{array}$ & $\begin{array}{l}04 / 01 / 13-06 / 12 / 13 \\
03 / 08 / 13-10 / 22 / 13 \\
03 / 18 / 13-09 / 04 / 13 \\
03 / 01 / 13-11 / 05 / 13\end{array}$ & $\begin{array}{l}14.57-33.18 \\
10.99-33.34 \\
13.26-32.77 \\
10.86-31.38\end{array}$ & $\begin{array}{l}12.53-14.23 \\
11.73-11.17 \\
12.07-12.72 \\
11.52-10.77\end{array}$ & $\begin{array}{r}64(26) \\
198(81) \\
140(57) \\
219(90)\end{array}$ \\
\hline $\begin{array}{l}\text { Spotted seatrout Cynoscion } \\
\text { nebulosus }\end{array}$ & $\begin{array}{c}4 \mathrm{M} \\
9 \mathrm{M} \\
14 \mathrm{M} \\
37 \mathrm{M}\end{array}$ & $\begin{array}{c}\text { nd } \\
04 / 01 / 13-10 / 07 / 13 \\
04 / 04 / 13-10 / 18 / 13 \\
04 / 12 / 13-10 / 31 / 13\end{array}$ & $\begin{array}{c}\text { nd } \\
15.56-33.34 \\
16.38-32.77 \\
19.19-31.38\end{array}$ & \begin{tabular}{l}
\multicolumn{1}{c}{ nd } \\
$12.53-11.65$ \\
$12.63-11.3$ \\
$12.88-10.9$
\end{tabular} & $\begin{array}{c}0(0) \\
160(66) \\
167(68) \\
172(70)\end{array}$ \\
\hline Red drum Sciaenops ocellatus & $\begin{array}{c}4 \mathrm{M} \\
9 \mathrm{M} \\
14 \mathrm{M} \\
37 \mathrm{M}\end{array}$ & $\begin{array}{c}\text { nd } \\
06 / 11 / 13-11 / 23 / 13 \\
\text { nd } \\
06 / 17 / 13-10 / 28 / 13\end{array}$ & $\begin{array}{c}\text { nd } \\
13.76-33.34 \\
\text { nd } \\
19.94-31.38\end{array}$ & $\begin{array}{c}\text { nd } \\
14.22-10.33 \\
\text { nd } \\
13.65-10.98\end{array}$ & $\begin{aligned} 0 & (0) \\
126 & (52) \\
0 & (0) \\
133 & (55)\end{aligned}$ \\
\hline
\end{tabular}




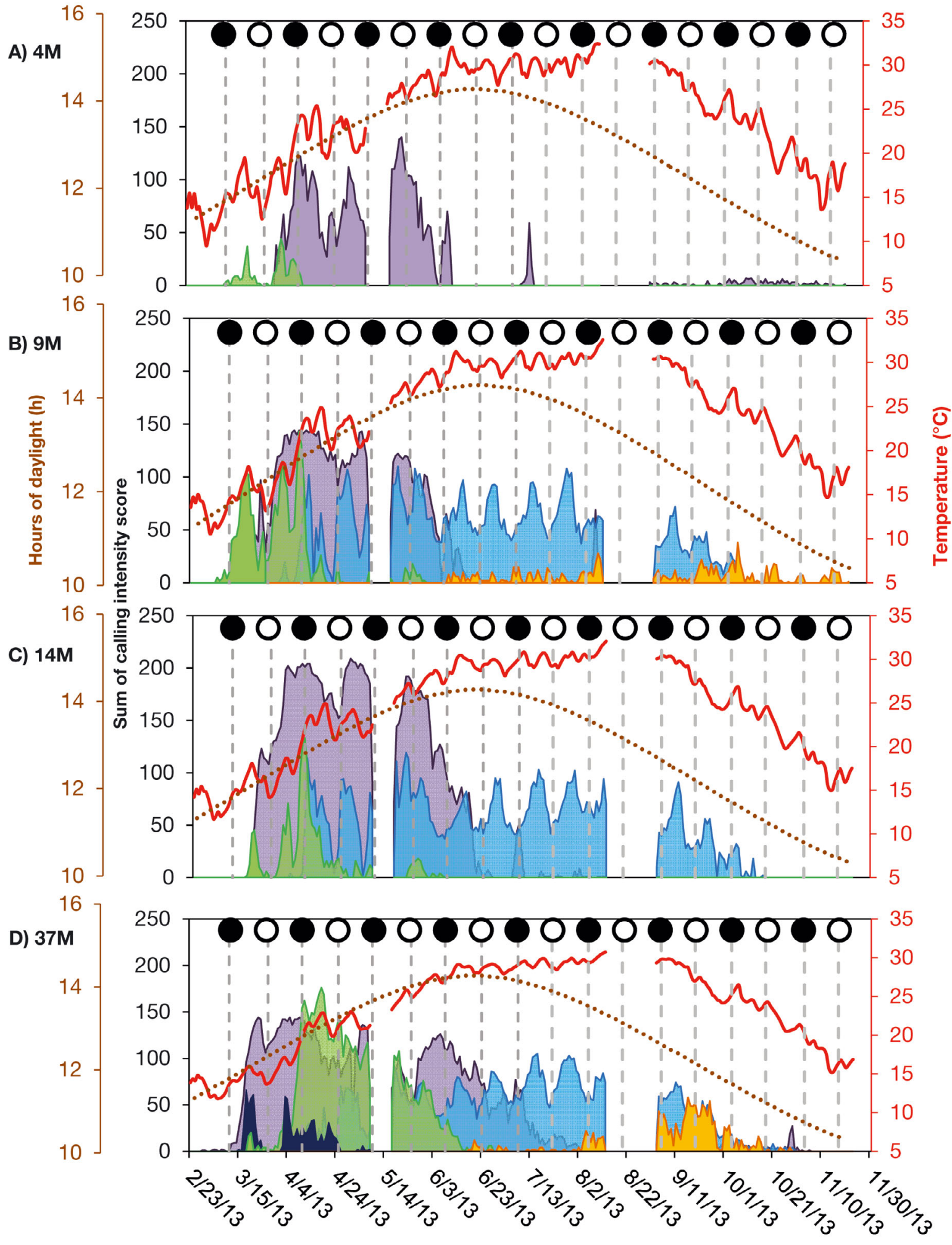

口oyster toadfish $\square$ spotted seatrout $\square$ silver perch $\square$ black drum $\square$ red drum

Fig. 5. Seasonal patterns of fish sound production that dominated the fish soundscape in the May River, South Carolina. Sum of calling intensity scores per night at (A) Stn 4M, (B) Stn 9M, (C) Stn 14M, and (D) Stn 37M. Also shown are water temperature (red line), hours of daylight (brown dotted line), and new (dark circles) and full (white circles) moon phases. Two gaps in data (8-17 May and 13 August - 3 September 2013) correspond to breaks between deployments due to maintenance of equipment 
Based on captive studies that illustrated a positive relationship between the amount of calling and spawning success in sciaenids (Connaughton \& Taylor 1996, Luczkovich et al. 1999, Lowerre-Barbieri et al. 2008, Montie et al. 2016, 2017), we speculated that chorusing (i.e. calling intensity score $=3$ ) was a reliable indicator of spawning for silver perch, spotted seatrout, and red drum (Table 4). Following this hypothesis, we estimated the start and end dates for the spawning season as well as the number of days that chorusing occurred for each species at the 4 locations (Table 4). Interestingly, we detected a temporal shift in the start and end dates for silver perch chorusing at the different stations (Table 4, Fig. 5). Chorusing was first detected at Stn 9M, then 4 d later at Stn 14M, and 23 d later at Stn 37M. This shift followed a differential heating pattern observed at these sampling locations, with water warming more rapidly at stations closer to the source of the May River (i.e. $9 \mathrm{M}>14 \mathrm{M}>37 \mathrm{M}$ ).

We estimated the number of spawning days that occurred within the reproductive season for silver perch, spotted seatrout, and red drum based on the detection of chorusing aggregations (Table 4). Silver perch chorusing was detected anywhere from 1 to $19 \%$ of the days monitored, depending upon the station. Based on chorusing, spawning aggregations of silver perch were detected more frequently at the mouth (i.e. $37 \mathrm{M}=47 \mathrm{~d}$ ), and less towards the source (i.e. $14 \mathrm{M}=15 \mathrm{~d}>9 \mathrm{M}=13 \mathrm{~d}>4 \mathrm{M}=3 \mathrm{~d}$ ). . Spotted seatrout had the longest spawning season, with cho- rusing detection percentages ranging from 37 to $53 \%$ of the days monitored. This species chorused for $129 \mathrm{~d}$ at Stn 9M, $91 \mathrm{~d}$ at Stn 14M, and $110 \mathrm{~d}$ at Stn 37M. Red drum chorusing was only detected at the mouth of the May River (i.e. 37M). Red drum had the shortest spawning season, and chorusing was detected only $5 \%$ of the days monitored. This percentage equated to $13 \mathrm{~d}$ in which chorusing was detected.

We observed temporal synchrony in peaks of calling intensity among the various stations for silver perch, oyster toadfish, and spotted seatrout (Figs. 5 \& 6). For silver perch, we detected peak dates in calling intensity on 20 March, 3 April, and 10 April 2013 at Stns 4M, 9M, and 14M, respectively. Silver perch calling at Stn $37 \mathrm{M}$ was delayed; therefore, calling at Stn $37 \mathrm{M}$ was less in synchrony with calling at the other stations (Fig. 5). For oyster toadfish, we detected peak dates of calling that centered on 14 April, 5 May, and 23 May 2013 at Stns 4M, 9M, and 14M, respectively; peak calling at Stn $37 \mathrm{M}$ was less in synchrony with calling at the other stations. Spotted seatrout exhibited synchronistic patterns of peak calling intensity at Stns 9M, 14M, and 37M (Figs. 5 \& $6)$. The patterns between Stns $9 \mathrm{M}$ and $37 \mathrm{M}$ became more synchronous during the summer. For spotted seatrout, peak intensities were observed around the first and third quarter lunar phases (Figs. 5 \& 6). We found a significant positive correlation for calling intensity patterns of silver perch, spotted seatrout, and oyster toadfish between stations (Table 5). Stations closer to each other had higher correlation

Table 4. Seasonal timelines, temperatures, hours of daylight, and frequency in which chorusing was detected for each fish species at each station. \% of days chorusing = the number of days chorusing divided by the number of days monitored multiplied by 100; temperature and daylight ranges are given as minimum to maximum; nd: calling was not detected

\begin{tabular}{|c|c|c|c|c|c|c|}
\hline Species & Station & $\begin{array}{l}\text { Date range } \\
(\mathrm{mm} / \mathrm{dd} / \mathrm{yy})\end{array}$ & $\begin{array}{l}\text { Temperature } \\
\text { range }\left({ }^{\circ} \mathrm{C}\right)\end{array}$ & $\begin{array}{l}\text { Daylight } \\
\text { range }(\mathrm{h})\end{array}$ & $\begin{array}{l}\text { Number (and \%) } \\
\text { of days chorusing }\end{array}$ & $\begin{array}{l}\text { Total chorus } \\
\text { duration (h) }\end{array}$ \\
\hline $\begin{array}{l}\text { Silver perch Bairdiella } \\
\text { chrysoura }\end{array}$ & $\begin{array}{c}4 \mathrm{M} \\
9 \mathrm{M} \\
14 \mathrm{M} \\
37 \mathrm{M}\end{array}$ & $\begin{array}{l}04 / 02 / 13-04 / 04 / 13 \\
03 / 16 / 13-04 / 10 / 13 \\
03 / 20 / 13-04 / 17 / 13 \\
04 / 08 / 13-06 / 02 / 13\end{array}$ & $\begin{array}{l}16.68-21.34 \\
12.18-23.54 \\
13.26-24.93 \\
16.86-28.00\end{array}$ & $\begin{array}{l}12.57-12.63 \\
12.00-12.83 \\
12.13-13.05 \\
12.77-14.15\end{array}$ & $\begin{array}{c}3(1) \\
13(5) \\
15(5) \\
47(19)\end{array}$ & $\begin{array}{c}<1 \\
51 \\
63 \\
269\end{array}$ \\
\hline Oyster toadfish Opsanus tau & $\begin{array}{c}4 \mathrm{M} \\
9 \mathrm{M} \\
14 \mathrm{M} \\
37 \mathrm{M}\end{array}$ & $\begin{array}{c}\text { nd } \\
\text { nd } \\
04 / 03 / 13-05 / 31 / 13 \\
\text { nd }\end{array}$ & $\begin{array}{c}\text { nd } \\
\text { nd } \\
16.38-28.79 \\
\text { nd }\end{array}$ & $\begin{array}{c}\text { nd } \\
\text { nd } \\
12.6-14.12 \\
\text { nd }\end{array}$ & $\begin{array}{c}0(0) \\
0(0) \\
50(20) \\
0(0)\end{array}$ & $\begin{array}{c}0 \\
0 \\
609 \\
0\end{array}$ \\
\hline $\begin{array}{l}\text { Spotted seatrout Cynoscion } \\
\text { nebulosus }\end{array}$ & $\begin{array}{c}4 \mathrm{M} \\
9 \mathrm{M} \\
14 \mathrm{M} \\
37 \mathrm{M}\end{array}$ & $\begin{array}{c}\text { nd } \\
04 / 10 / 13-09 / 22 / 13 \\
04 / 11 / 13-09 / 18 / 13 \\
04 / 26 / 13-09 / 17 / 13\end{array}$ & $\begin{array}{c}\text { nd } \\
19.51-33.34 \\
20.20-32.77 \\
20.21-31.38\end{array}$ & $\begin{array}{c}\text { nd } \\
12.83-12.13 \\
12.85-13.23 \\
13.32-12.3\end{array}$ & $\begin{aligned} 0(0) \\
129(53) \\
91(37) \\
110(45)\end{aligned}$ & $\begin{array}{c}0 \\
496 \\
538 \\
409\end{array}$ \\
\hline $\begin{array}{l}\text { Red drum Sciaenops } \\
\text { ocellatus }\end{array}$ & $\begin{array}{c}4 \mathrm{M} \\
9 \mathrm{M} \\
14 \mathrm{M} \\
37 \mathrm{M}\end{array}$ & $\begin{array}{c}\text { nd } \\
\text { nd } \\
\text { nd } \\
09 / 04 / 13-09 / 24 / 13\end{array}$ & $\begin{array}{c}\text { nd } \\
\text { nd } \\
\text { nd } \\
26.11-30.93\end{array}$ & $\begin{array}{c}\text { nd } \\
\text { nd } \\
\text { nd } \\
12.72-12.07\end{array}$ & $\begin{array}{r}0(0) \\
0(0) \\
0(0) \\
13(5)\end{array}$ & $\begin{array}{c}0 \\
0 \\
0 \\
27\end{array}$ \\
\hline
\end{tabular}


A) $9 \mathrm{M}$

000000000000000000

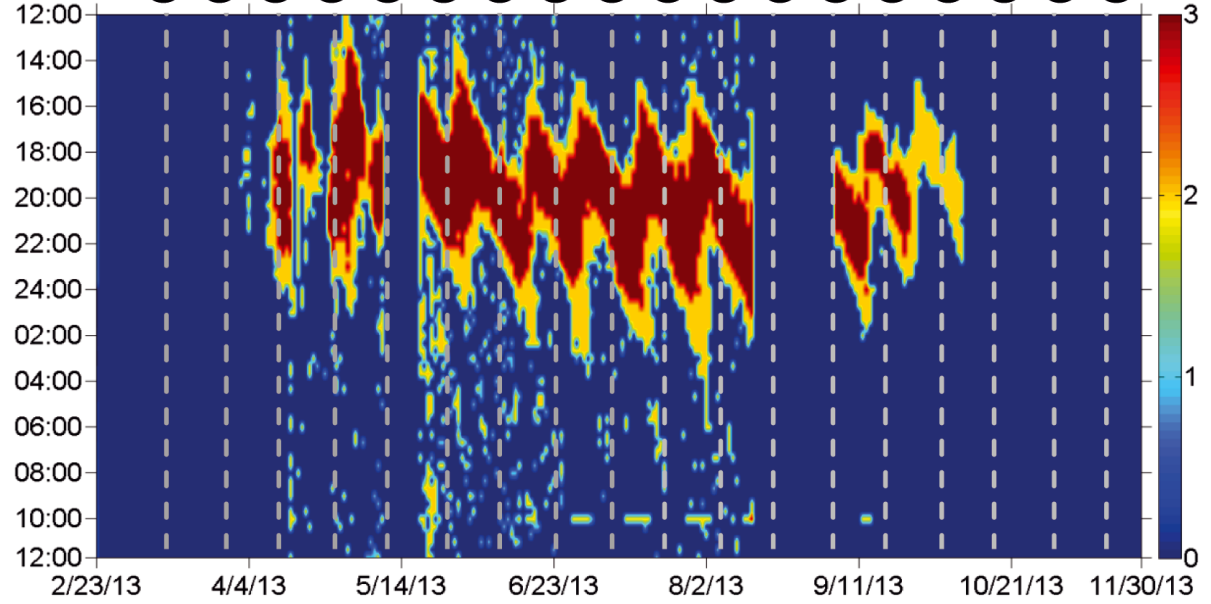

B) $14 \mathrm{M}$

000000000000000000

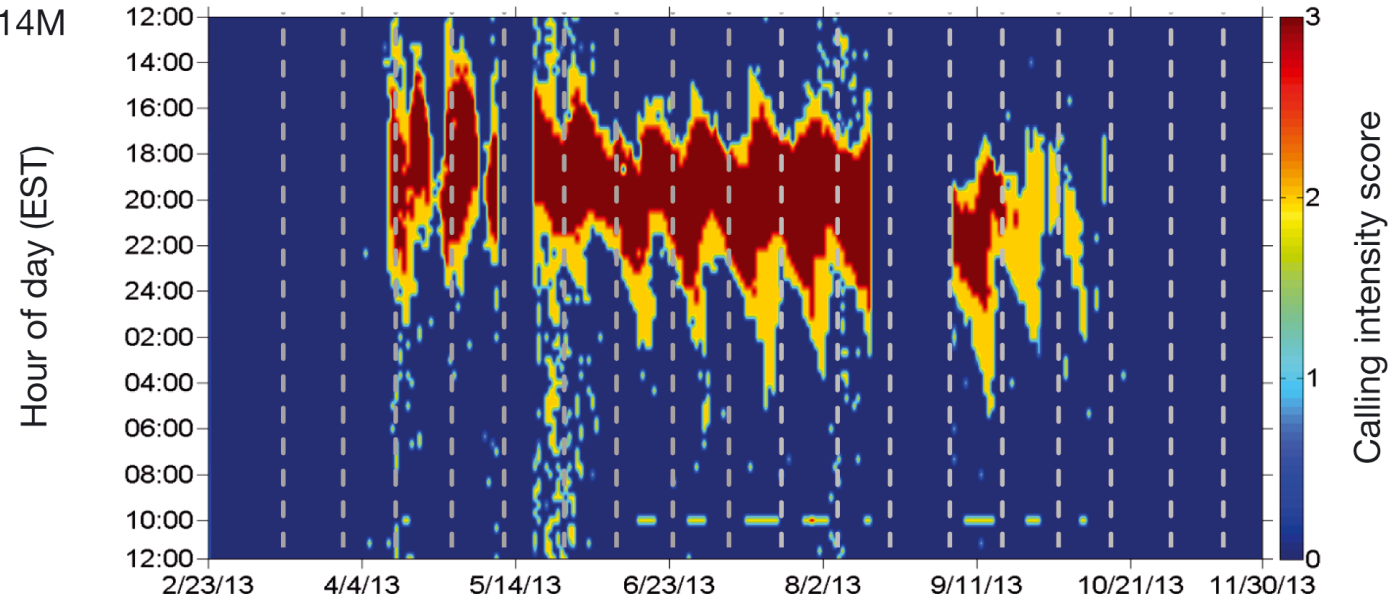

C) $37 \mathrm{M}$

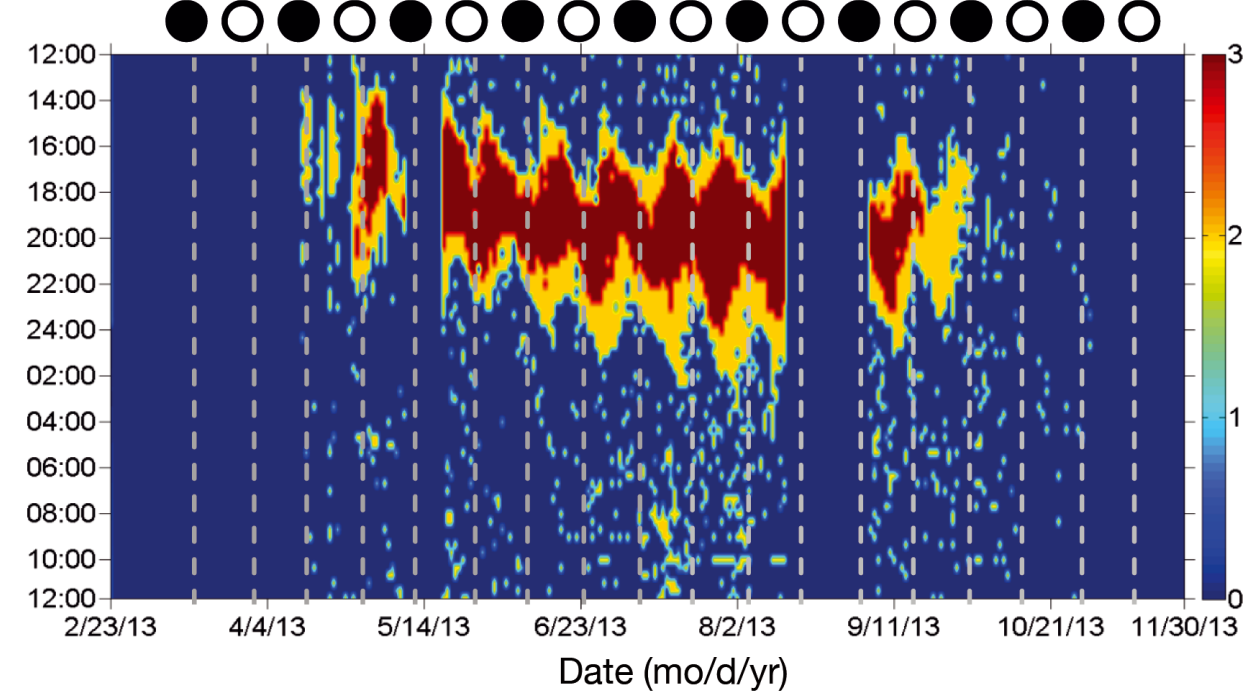

Fig. 6. Heat maps representing calling intensity scores of spotted seatrout Cynoscion nebulosus at Stns (A) 9M, (B) 14M, and (C) 37M. Warmer (cooler) colors indicate higher (lower) intensity scores; dark and white circles correspond to new and full moon, respectively. Time is shown between noon and noon of the next day (EST: Eastern Standard Time). Two gaps in data (8-17 May and 13 August - 3 September 2013) correspond to breaks between deployments due to maintenance of equipment 
coefficients than the stations located further apart (Table 5).

We detected daily patterns in calling and chorusing that were unique to each species. All detected sciaenids followed a general daily pattern in calling, with peak sound production occurring at dusk (Fig. 7). Seasonally and in some cases spatially, black drum, silver perch, and the initial season of oyster toadfish and spotted seatrout calling overlapped; however, peak sound production during the day varied for each of these species. Black drum started to call $1 \mathrm{~h}$ before sunset, with peak sound production at dusk. Silver perch exhibited long chorus durations; calling peaked $3 \mathrm{~h}$ after sunset and continued into the early morning hours. Spotted seatrout calling increased $1 \mathrm{~h}$ before sunset, with a peak occurring $2 \mathrm{~h}$ after sunset and continuing for $1 \mathrm{~h}$ before the intensity began to decrease. Later in the season at some stations, spotted seatrout and red drum calling overlapped; however, red drum began to call earlier in the day. Red drum began to call $3 \mathrm{~h}$ before sunset, with peak sound production occurring at dusk. Calling decreased shortly after sunset.

The chorus duration per evening varied over the recording period for silver perch, spotted seatrout, and red drum (Fig. 6; data not shown for silver perch and red drum). The duration of silver perch chorus-
Table 5. Pearson correlation coefficients $\left(\mathrm{r}_{\mathrm{S}}\right)$ and $\mathrm{p}$-values of calling intensity scores between stations and corresponding distances; na: correlation was not completed because calling was not detected at 1 or both stations. Values in bold are significant at $\mathrm{p}<0.05$

\begin{tabular}{|c|c|c|c|c|}
\hline Species & Stations & $r_{S}$ & $\mathrm{p}$ & $\begin{array}{l}\text { Distance } \\
(\mathrm{km})\end{array}$ \\
\hline $\begin{array}{l}\text { Silver perch } \\
\text { Bairdiella } \\
\text { chrysoura }\end{array}$ & $\begin{array}{c}4 \mathrm{M} \text { vs } 9 \mathrm{M} \\
9 \mathrm{M} \text { vs } 14 \mathrm{M} \\
4 \mathrm{M} \text { vs } 14 \mathrm{M} \\
14 \mathrm{M} \text { vs } 37 \mathrm{M} \\
9 \mathrm{M} \text { vs } 37 \mathrm{M} \\
4 \mathrm{M} \text { vs } 37 \mathrm{M}\end{array}$ & $\begin{array}{l}\mathbf{0 . 8 0} \\
0.75 \\
\mathbf{0 . 6 4} \\
\mathbf{0 . 5 1} \\
\mathbf{0 . 1 9} \\
0.09\end{array}$ & $\begin{array}{l}<0.01 \\
<0.01 \\
<0.01 \\
<0.01 \\
<0.01 \\
0.15\end{array}$ & $\begin{array}{c}3.6 \\
4.7 \\
8.3 \\
13.3 \\
18.0 \\
21.6\end{array}$ \\
\hline $\begin{array}{l}\text { Oyster toadfish } \\
\text { Opsanus tau }\end{array}$ & $\begin{array}{c}4 \mathrm{M} \text { vs } 9 \mathrm{M} \\
9 \mathrm{M} \text { vs } 14 \mathrm{M} \\
4 \mathrm{M} \text { vs } 14 \mathrm{M} \\
14 \mathrm{M} \text { vs } 37 \mathrm{M} \\
9 \mathrm{M} \text { vs } 37 \mathrm{M} \\
4 \mathrm{M} \text { vs } 37 \mathrm{M}\end{array}$ & $\begin{array}{l}0.85 \\
0.96 \\
0.83 \\
0.85 \\
0.80 \\
0.59\end{array}$ & $\begin{array}{l}<0.01 \\
<0.01 \\
<0.01 \\
<0.01 \\
<0.01 \\
<0.01\end{array}$ & $\begin{array}{c}3.6 \\
4.7 \\
8.3 \\
13.3 \\
18.0 \\
21.6\end{array}$ \\
\hline $\begin{array}{l}\text { Spotted seatrout } \\
\text { Cynoscion } \\
\text { nebulosus }\end{array}$ & $\begin{array}{c}4 \mathrm{M} \text { vs } 9 \mathrm{M} \\
9 \mathrm{M} \text { vs } 14 \mathrm{M} \\
4 \mathrm{M} \text { vs } 14 \mathrm{M} \\
14 \mathrm{M} \text { vs } 37 \mathrm{M} \\
9 \mathrm{M} \text { vs } 37 \mathrm{M} \\
4 \mathrm{M} \text { vs } 37 \mathrm{M}\end{array}$ & $\begin{array}{c}\text { na } \\
\mathbf{0 . 9 4} \\
\text { na } \\
\mathbf{0 . 8 6} \\
\mathbf{0 . 8 8} \\
\text { na }\end{array}$ & $\begin{array}{c}\text { na } \\
<0.01 \\
\text { na } \\
<0.01 \\
<0.01 \\
\text { na }\end{array}$ & $\begin{array}{c}\text { na } \\
4.7 \\
\text { na } \\
13.3 \\
18.0 \\
\text { na }\end{array}$ \\
\hline $\begin{array}{l}\text { Red drum } \\
\text { Sciaenops } \\
\text { ocellatus }\end{array}$ & $\begin{array}{c}4 \mathrm{M} \text { vs } 9 \mathrm{M} \\
9 \mathrm{M} \text { vs } 14 \mathrm{M} \\
4 \mathrm{M} \text { vs } 14 \mathrm{M} \\
14 \mathrm{M} \text { vs } 37 \mathrm{M} \\
9 \mathrm{M} \text { vs } 37 \mathrm{M} \\
4 \mathrm{M} \text { vs } 37 \mathrm{M}\end{array}$ & $\begin{array}{c}\text { na } \\
\text { na } \\
\text { na } \\
\text { na } \\
\mathbf{0 . 3 2} \\
\text { na }\end{array}$ & $\begin{array}{c}\text { na } \\
\text { na } \\
\text { na } \\
\text { na } \\
<\mathbf{0 . 0 1} \\
\text { na }\end{array}$ & $\begin{array}{c}\text { na } \\
\text { na } \\
\text { na } \\
\text { na } \\
18.0 \\
\text { na }\end{array}$ \\
\hline
\end{tabular}

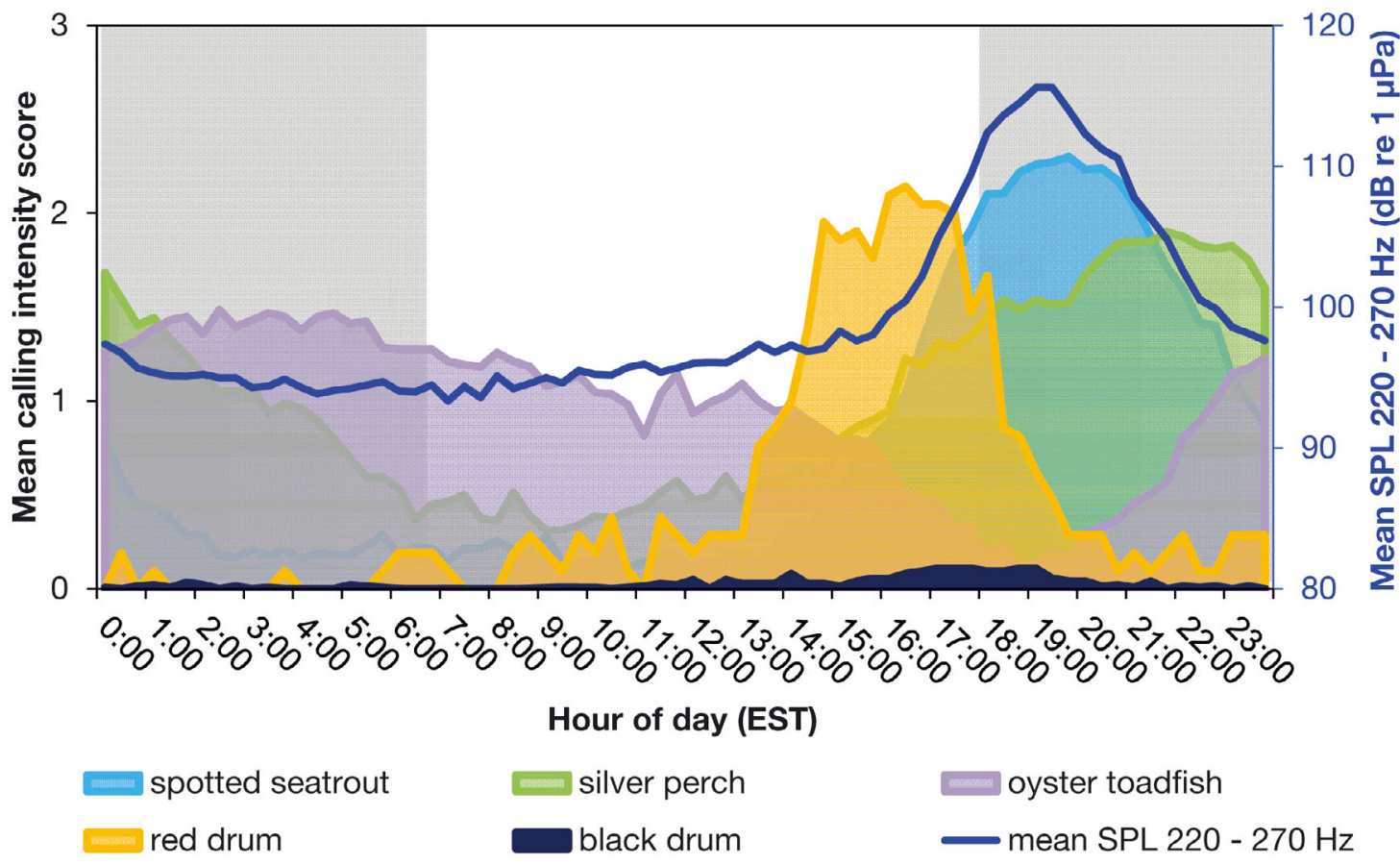

Fig. 7. Daily patterns of sound production level (SPL) of soniferous fishes in the May River, South Carolina. For each fish species, the calling intensity score was averaged from 00:00 to 23:40 h every 20 min at Stn 37M. We calculated mean received SPL between 220 and $270 \mathrm{~Hz}$, which presents the peak frequency of spotted seatrout Cynoscion nebulosus chorusing (dark blue). Shaded gray boxes represent the average dark period 
ing varied between 0.3 and $13 \mathrm{~h}$. The longest silver perch chorus was detected on 10 April 2013 at Stn $14 \mathrm{M}$ and lasted for $13 \mathrm{~h}$. On the same day, we detected the longest chorus at Stn 9M, which lasted $5 \mathrm{~h}$. The longest chorusing episode at Stn $37 \mathrm{M}$ was recorded on 17 April 2013 and lasted $12 \mathrm{~h}$. During the reproductive season, we estimated that silver perch chorused for approximately $269 \mathrm{~h}$ at Stn 37M; $63 \mathrm{~h}$ at $\mathrm{Stn} 14 \mathrm{M}_{i} 51 \mathrm{~h}$ at $\mathrm{Stn} 9 \mathrm{M}_{i}$ and $0.13 \mathrm{~h}$ at $\mathrm{Stn} 4 \mathrm{M}$ (Table 4). The duration of spotted seatrout chorusing varied between 0.3 and $9 \mathrm{~h}$. The longest spotted seatrout chorus occurred for $9 \mathrm{~h}$ at Stn $9 \mathrm{M}$ on 29 April and 29 July 2013; for $8 \mathrm{~h}$ at Stn $14 \mathrm{M}$ on 28 April 2013; and for $8 \mathrm{~h}$ at Stn $37 \mathrm{M}$ on 28 July 2013. For the reproductive season of spotted seatrout, we estimated the total chorusing time to be $538 \mathrm{~h}$ at Stn $14 \mathrm{M}, 496 \mathrm{~h}$ at Stn $9 \mathrm{M}$, and $409 \mathrm{~h}$ at Stn $37 \mathrm{M}$ (Table 4). As stated previously, we only detected red drum chorusing aggregations at Stn $37 \mathrm{M}$. Chorus durations varied from 1 to $4 \mathrm{~h}$, with the longest chorus occurring on 17 September 2013. Over the entire reproductive season, we estimated that red drum chorused approximately $27 \mathrm{~h}$ (Table 4 ).

\section{Factors that influenced sound production}

Using a GLM, we tested whether certain factors (i.e. station, month, day length, temperature anomaly, lunar phase, and tidal range) significantly influenced the summed calling intensity per night. For silver perch, station, month, and temperature anomaly influenced calling intensity (Table 6). Calling activity at Stn $37 \mathrm{M}$ was higher than all other stations $(\mathrm{p}<$ 0.05). Peak calling occurred in April and was higher than in all other months $(p<0.05)$. For oyster toadfish, station, month, and lunar phase influenced calling activity (Table 6). Calling intensity at Stn 14M was higher than calling at Stns 9M and 37M ( $p<$ $0.05)$. Oyster toadfish calling was more frequent during the months of April and May as compared to all other months $(p<0.05)$. Calling intensity on the full moon and third quarter were higher than calling on the new moon ( $p<0.05)$. For spotted seatrout, station, month, day length, temperature anomaly, and lunar phase significantly influenced sound production (Table 6). Calling intensity at Stn $4 \mathrm{M}$ was lower than the intensity observed at Stns 9M, 14M, and 37M ( p < 0.05). Calling intensity was the highest in June, July, and August compared to calling in April, May, September, and October $(p<0.05)$. Calling intensity of spotted seatrout increased as the amount of daylight lengthened. Drops in temperature (i.e. a negative
Table 6. Results of general linear models that tested the significance of specific variables on the amount of calling per night. Values in bold are significant at $p<0.05$

\begin{tabular}{|lcrr|}
\hline & $\mathrm{df}$ & $F$ & $\mathrm{p}$ \\
\hline Silver perch Bairdiella chrysoura & & & \\
Station & 3 & $\mathbf{4 1 . 5 5}$ & $<\mathbf{0 . 0 1}$ \\
Month & 3 & $\mathbf{6 . 3 8}$ & $<\mathbf{0 . 0 1}$ \\
Day length & 1 & 1.70 & 0.20 \\
Temperature anomaly & 1 & $\mathbf{5 . 1 5}$ & $\mathbf{0 . 0 2}$ \\
Lunar phase & 3 & 1.88 & 0.14 \\
Tidal range & 1 & 1.06 & 0.30 \\
Oyster toadfish Opsanus tau & & & \\
Station & 3 & $\mathbf{6 0 . 1 7}$ & $<\mathbf{0 . 0 1}$ \\
Month & 6 & $\mathbf{1 5 3 . 8 7}$ & $<\mathbf{0 . 0 1}$ \\
Day length & 1 & 2.50 & 0.12 \\
Temperature anomaly & 1 & 2.57 & 0.11 \\
Lunar phase & 3 & $\mathbf{4 . 7 7}$ & $<\mathbf{0 . 0 1}$ \\
Tidal range & 1 & 0.17 & 0.68 \\
Spotted seatrout Cynoscion nebulosus & & \\
Station & 3 & $\mathbf{1 2 5 . 2 6}$ & $<\mathbf{0 . 0 1}$ \\
Month & 5 & $\mathbf{1 4 . 1 4}$ & $<\mathbf{0 . 0 1}$ \\
Day length & 1 & $\mathbf{3 4 . 7 6}$ & $<\mathbf{0 . 0 1}$ \\
Temperature anomaly & 1 & $\mathbf{3 8 . 5 3}$ & $<\mathbf{0 . 0 1}$ \\
Lunar phase & 3 & $\mathbf{1 1 . 2 4}$ & $<\mathbf{0 . 0 1}$ \\
Tidal range & 1 & 2.64 & 0.11 \\
& & & \\
\hline
\end{tabular}

anomaly) decreased spotted seatrout calling, while rises in temperature (i.e. a positive anomaly) increased sound production (Table 6 ; Fig. S5). In addition, we observed cyclic patterns in calling intensity that followed the lunar phase. More calling was detected on the first quarter compared to calling on the new moon and on the third quarter compared to the full moon $(p<0.05)$. For black drum, silver perch, oyster toadfish, and spotted seatrout, separate linear regressions indicated that negative temperature anomalies decreased calling intensity, while positive temperature anomalies increased sound production (Fig. S5; $\mathrm{p}<0.05$ ).

\section{DISCUSSION}

Advances in recording systems within the field of passive acoustics allow scientists to study in detail the soundscapes of marine ecosystems. Long-term recordings of a large, tidal river revealed 5 species of fish that dominated the estuarine soundscape, which included calling of black drum and oyster toadfish and chorusing of silver perch, spotted seatrout, and red drum. Spatially, the highest species diversity was detected at the mouth of the May River, and the lowest diversity was observed near the source. We observed that fish courtship sounds followed distinct 
temporal patterns over seasonal, lunar, and daily time scales, and that temperature anomalies within a courtship season significantly influenced calling intensity and duration. Across locations, we detected temporal synchrony in peaks of calling intensity. These findings provide baseline information on the temporal rhythms of sound production and estimates of spawning patterns for 5 fish species that dominate the soundscape. These acoustic data may be especially helpful in comparing the timing and length of reproductive seasons from one year to the next, where variation may be driven by fluctuations in climate. It is possible that differences in these calling parameters (i.e. timing, length, and frequency) may influence year class strength of recreationally important fish species like spotted seatrout and red drum and that passive acoustic monitoring provides a powerful analysis tool.

\section{Identifying fish calls and chorusing in large data sets}

We reported species-specific frequency ranges of calling for black drum, oyster toadfish, silver perch, spotted seatrout, and red drum that were similar to the frequency ranges reported in other studies (Tavolga 1958, Sprague 2000, Gilmore 2003, Luczkovich et al. 2008, Maruska \& Mensinger 2009, Wall et al. 2013). Using specific frequency ranges driven from PSD analysis, we applied filters and performed SPL analysis to determine if SPL correlated with calling intensity. This approach worked for spotted seatrout and silver perch that produced loud choruses well above the background noise of snapping shrimp (genera Alpheus and Synalpheus) but not for oyster toadfish, black drum, and red drum that had quieter calls and choruses. SPL analysis might be a way to detect presence or absence of fish calls but will not work as the sole feature in signal detection of specific fish species.

Recent advances in automatic speech recognition have enabled the automatic analysis of bioacoustic signals originating from birds (Trifa et al. 2008, Potamitis et al. 2014, de Oliveira et al. 2015, Ganchev et al. 2015), amphibians (Acevedo et al. 2009), terrestrial mammals (Parsons 2001, Dylla et al. 2013, Zeppelzauer et al. 2015), and marine mammals (Kandia \& Stylianou 2006, Helble et al. 2012, Pace et al. 2012, Baumann-Pickering et al. 2013). However, there are not many studies where signal detectors have been created to detect fish acoustic signals, especially successful ones that can identify fish calling amidst a noisy background. Recently, automatic call recogni- tion was applied to identify Lusitanian toadfish Halobatrachus didactylus vocalizations in Portugal and red grouper Epinephelus morio calls on the West Florida Shelf, but these soundscapes are quieter than estuaries and the diversity of soniferous fishes was less than in the May River (Wall et al. 2014, Vieira at al. 2015). There is a need to develop signal detectors to detect and quantify fish calling amidst a noisy, estuarine soundscape in order to shorten the time of analysis when analyzing large acoustic data sets.

\section{Spatial patterns in sound production}

We observed spatial patterns of fish sound production in the May River similar to previous studies (Montie et al. 2015). Calling was more frequent at the mouth compared to the source. This pattern may suggest that locations near the source are unsuitable spawning habitats for sciaenids and oyster toadfish. The source of the May River experiences intense fluctuations in environmental parameters (salinity, temperature, and $\mathrm{pH}$ ) while the mouth of the river experiences less variability. In addition, the source has lower salinity and $\mathrm{pH}$, which can be indicative of lower water quality. Lower salinity, pH, and dissolved oxygen have been shown to negatively affect spawning as well as egg and larval survival in Atlantic croaker and spot (Miglarese et al. 1982, Barbieri et al. 1994, Buzzelli et al. 2002, Peterson et al. 2004). Red drum choruses were detected only at the mouth of the May River, indicating that this location was a preferred spawning hotspot in this estuary, similar to the findings of Montie et al. (2015). This area is approximately $18 \mathrm{~m}$ deep, has a high salinity, and opens to Calibogue Sound connecting the May River to the Atlantic Ocean. This spatial pattern (i.e. mouth of estuaries that are deep) seems to be preferred by black drum, silver perch, and red drum (Holt et al. 1981, Johnson \& Funicelli 1991, LowerreBarbieri et al. 2008, Luczkovich et al. 2008).

\section{Patterns of sound production}

The seasonal patterns of courtship sounds we observed in this study were similar to the patterns of calling reported in other studies centered along the Gulf of Mexico and Northwestern Atlantic coastlines. In North Carolina, South Carolina, and Florida, sound production of black drum was observed between January and April (Nieland \& Wilson 1993, Locascio \& Mann 2011, Montie et al. 2015, Rice et al. 
2016), silver perch between February and June (Mok \& Gilmore 1983, Luczkovich et al. 2008, Montie et al. 2015), oyster toadfish between February and November (Gudger 1910, Tavolga 1958, Amorim et al. 2006, Montie et al. 2015), spotted seatrout between May and September (Riekerk et al. 1997, Luczkovich et al. 2008, Lowerre-Barbieri et al. 2008, Montie et al. 2015), and red drum between September and November (Johnson \& Funicelli 1991, Montie et al. 2015). Because we deployed recorders for 9 mo with $10 \%$ daily time coverage, we were able to estimate the dates for the initiation and termination of the reproductive season, its overall duration, and the number of days and hours in which chorusing occurred for 5 fish species, which comprised most of the fish soundscape.

Long-term monitoring allowed us to examine environmental parameters that significantly influenced calling intensity. Location (station), month, temperature anomaly, and lunar phase were significant variables that affected calling intensity. Temperature anomalies, which can change from one year to another, significantly influenced calling intensity of black drum, silver perch, oyster toadfish, and spotted seatrout. Positive temperature anomalies increased calling, while negative temperature anomalies decreased sound production. These findings are similar to reports from captive studies with spotted seatrout, weakfish, oyster toadfish, and red drum, where higher temperatures increased the amount of calling and the number of pulses in a call (Fine 1978, Connaughton et al. 2000, Maruska \& Mensinger 2009, Montie et al. 2016, 2017).

The lunar phase significantly influenced calling intensity of oyster toadfish and spotted seatrout. We detected pronounced cyclic patterns in the amount of calling and chorus duration for spotted seatrout. Other studies have provided some evidence that spotted seatrout calling and spawning are related to the lunar cycle. Gilmore (1994) discovered that spotted seatrout calling occurred most often around the full moon. However, our findings indicate different patterns than the findings observed by Gilmore (1994). Longer chorusing episodes with earlier start times occurred on the first and third quarter phases rather than on the full moon as observed by Gilmore (1994). From an energetic and biomechanical perspective, it is more efficient for spotted seatrout to spawn on the neap tides when the tidal range is smaller and the currents are slower, and muscle movement and energy can be used more for sound production and less for fighting a swift current. However, previous studies showed that toadfish calling does not increase oxygen consumption on a whole animal basis (Amorim et al. 2002).

We found that black drum, silver perch, spotted seatrout, and red drum exhibited synchronized daily patterns of calling. Similar to other studies, black drum and red drum peak calling occurred in the late afternoon and spotted seatrout and silver perch a few hours after sunset (Tavolga 1958, Mok \& Gilmore 1983, Gilmore 2003, Locascio \& Mann 2008, 2011, Lowerre-Barbieri et al. 2008, Luczkovich et al. 2008, Maruska \& Mensinger 2009). Sciaenids most likely spawn at dusk to limit the predation on eggs by many juvenile and adult fishes (Holt et al. 1985). Interestingly, spatial and seasonal overlap of calling occurred for silver perch and spotted seatrout in the spring, and for red drum and spotted seatrout in the fall, yet the maximum daily peak in calling was different for each species. This strategy may lead to a more successful spawn because it limits competition for acoustic space. Similar to findings from other studies, we showed that oyster toadfish were calling sporadically day and night (Fine et al. 1977, Fine \& Thorson 2008).

\section{Synchronized calling may facilitate reproductive success}

Synchrony of calling over seasonal, lunar, and daily time scales occurred at the 4 stations that were separated over distances between 3.6 and $22 \mathrm{~km}$. It is very unlikely that fish travel these distances during one evening and could be recorded at these different stations. It is more possible that fish produce courtship sounds, attract mates to a specific location, form spawning aggregations, and then release gametes in a tight formation to ensure fertilization. In addition, the May River has very complicated topography, with several creeks, meanders, and sand bars, which will decrease how calls propagate away from their source. Therefore, it is very unlikely that the same call could be recorded on 2 different recorders, and it is much more likely that synchrony of calling over large spatial scales does occur.

The synchronized timing of individual calls in response to calling competition is very common in many insects and amphibians (Moore et al. 1989, Nityananda \& Balakrishnan 2009, Hartbauer et al. 2005). Studies have shown that synchronized calling can increase success of reproduction, attract females, and mislead predators (Vasconcelos et al. 2012, Greenfield et al. 2016). In our study, calling was more synchronized in time for stations that were closer to 
each other than for stations that were further apart. This observation may be related to differential, seasonal heating patterns observed among the stations, with stations closer to the source warming quicker than stations closer to the mouth.

\section{Detecting phenological shifts in reproduction}

Detecting dates when calling started and ended allowed us to estimate spawning seasons and estimate temperature ranges of spawning for each fish species. Interestingly, seasonal start dates of calling varied among the stations in the May River. Silver perch and spotted seatrout calls were first detected at Stn 9M, which was located closer to the source of the river, where water warmed more rapidly than stations closer to the mouth. Very often, photoperiod is considered the predominant factor in initiating the reproductive season in vertebrates (Gilmore 1994, Paul et al. 2008, Ubuka et al. 2013, Dawson 2015), but that would not explain temporal shifts in calling among monitored stations. This finding indicates that water temperature most likely plays a role in the timing and duration of spawning seasons.

This knowledge and approach is important because it could provide a model system to detect phenological shifts in the timing of reproduction associated with climate change. Traditional plankton sampling methods have shown that earlier spawning is occurring in some fish species. In California (USA), the phenology of 43 larval fish species was studied between 1951 and 2008, of which $39 \%$ of seasonal peaks in larval abundance occurred earlier each year (e.g. jack mackerel Trachurus symmetricus, Pacific hake Merluccius productus, Pacific mackerel Scomber japonicus), and $18 \%$ of the peaks were delayed in spring (e.g. chilipepper rockfish Sebastes goodie, California halibut Paralichthys californicus) (Asch 2015). As shown in captive experiments for spotted seatrout, red drum, and weakfish, spawning is strongly associated with the production of courtship sounds (Connaughton \& Taylor 1996, Montie et al. 2016, 2017). Therefore, listening to the estuarine soundscape may provide an easier, more efficient alternative to plankton sampling to track interannual variability in spawning. For example, warmer springs may cause earlier choruses of spotted seatrout, extending their spawning season, while warmer falls may cause later choruses of red drum, shortening their spawning season. These shifts may be important to ecosystem function because different species and trophic levels may vary in the degree of their response to climate change (Walther et al. 2002, Edwards \& Richardson 2004, Hoegh-Guldberg \& Bruno 2010). These differences may result in phenology mismatches between developing larvae and food availability or between developing larvae and predators (Hoegh-Guldberg \& Bruno 2010). In addition, shifts may cause the reproductive season of one species to overlap with another species, which may lead to competition for acoustic space and less than optimal conditions for reproduction. For example, warmer springs may cause earlier choruses of spotted seatrout, which could cause masking and interfere with the acoustic communication of oyster toadfish, silver perch, and black drum, affecting their spawning potential.

Tracking this inter-annual variability in courtship sounds may be helpful in fishery management and understanding how climate variability affects spawning and populations of black drum, silver perch, spotted seatrout, and red drum. Estimates of the dates for the initiation and termination of the reproductive season, its overall duration, and the number of days and hours in which chorusing occurred may be correlated to year class strength. When comparing multiple years of acoustic data, it is possible that years in which more hours of chorusing were detected would result in larger yields of egg biomass (Guest \& Lasswell 1978, Mok \& Gilmore 1983, Saucier \& Baltz 1993, Connaughton \& Taylor 1995, 1996, Luczkovich et al. 1999, Aalbers \& Drawbridge 2008, Montie et al. $2016,2017)$. Larger seasonal egg yields may result in a stronger year class. This hypothesis could be tested by comparing acoustic data to abundance data collected during South Carolina Department of Natural Resources electro-fishing and trammel net surveys conducted in this area since 1985 (Cain \& Dean 1976, Bozeman \& Dean 1980, Boynton et al. 2013). Other factors will influence fish abundance like predation, competition, and disease, but monitoring estuarine soundscapes may provide an understanding of maximum possible yields and the role of climate in influencing these patterns.

Acknowledgements. We thank Bob and Lee Brewer of May River Plantation for their support and for allowing us to use their community dock for our University of South Carolina Beaufort research vessel. We also thank the following individuals for their help in collection and analysis of acoustic data: Michael Powell, Matt Hoover, Rebecca Rawson, Steven Vega, Michaela Miller, Jenna MacKinnon, Alishia Zyer, Hannah Nylander-Asplin, Mackenna Neuroth, Claire Mueller, Wilma Sims, and Dr. Steve Arnott. This work was supported primarily by the Palmetto Bluff Conservancy and an ASPIRE I grant from the University of South Carolina. 
The Sea Island Institute of the University of South Carolina Beaufort and the Port Royal Sound Foundation provided additional funding for this research. In addition, the research reported in this publication was partially supported by the SC EPSCoR/IDeA Program under award number 17RE02. The views, perspective, and content do not necessarily represent the official views of the SC EPSCoR/IDeA Program.

\section{LITERATURE CITED}

Aalbers SA, Drawbridge MA (2008) White seabass spawning behavior and sound production. Trans Am Fish Soc 137:542-550

Acevedo MA, Corrada-Bravo CJ, Corrada-Bravo $\mathrm{H}$, Villanueva-Rivera LJ, Aide TM (2009) Automated classification of bird and amphibian calls using machine learning: a comparison of methods. Ecol Inform 4:206-214

Amorim MCP, McCracken ML, Fine ML (2002) Metabolic costs of sound production in the oyster toadfish, Opsanus tau. Can J Zool 80:830-838

Amorim MCP, Vasconcelos RO, Marques JF, Almada F (2006) Seasonal variation of sound production in the Lusitanian toadfish Halobatrachus didactylus. J Fish Biol 69:1892-1899

Asch RG (2015) Climate change and decadal shifts in the phenology of larval fishes in the California Current ecosystem. Proc Natl Acad Sci USA 112:E4065-E4074

Barbieri LR, Chittenden ME Jr, Jones CM (1994) Age, growth and mortality of Atlantic croaker, Micropogonias undulatus, in the Chesapeake Bay region, with a discussion of apparent geographic changes in population dynamics. Fish Bull 92:1-12

Baumann-Pickering S, McDonald MA, Simonis AE, Solsona Berga A and others (2013) Species-specific beaked whale echolocation signals. J Acoust Soc Am 134:2293-2301

Beckman DW, Wilson CA, Stanley AL (1988) Age and growth of red drum, Sciaenops ocellatus, from offshore waters of the northern Gulf of Mexico. Fish Bull 87:17-28

Beebee TJC (1995) Amphibian breeding and climate change. Nature 374:219-220

Boynton JB, Van Dolah RF, Arendt MD, Reichert MJ (2013) Final report: comprehensive spatial data on biological resources and uses in Southeastern Coastal Waters of the U.S. Southeast Coastal Ocean Observing Regional Association, Charleston, SC. www.dnr.sc.gov/GIS/pdf/GSAA FinalReport.pdf

Bozeman EL, Dean JM (1980) The abundance of estuarine larval and juvenile fish in a South Carolina intertidal creek. Estuaries 3:89-97

*Bown JL, Li SH, Bhagabati N (1999) Long-term trend toward earlier breeding in an American bird: a response to global warming? Proc Natl Acad Sci USA 96: 5565-5569

Brown CA, Jackson GA, Holt SA, Holt GJ (2005) Spatial and temporal patterns in modeled particle transport to estuarine habitat with comparisons to larval fish settlement patterns. Estuar Coast Shelf Sci 64:33-46

Brown-Peterson NJ, Warren JR (2002) The reproductive biology of spotted seatrout, Cynoscion nebulosus, along the Mississippi Gulf coast. Gulf Mex Sci 19:61-73

Brown-Peterson NJ, Thomas P, Arnold C (1988) Reproductive biology of the spotted seatrout, Cynoscion nebulosus, in South Texas. Fish Bull 86:373-387
Brown-Peterson NJ, Peterson MS, Nieland DL, Murphy MD, Taylor RG, Warren JR (2002) Reproductive biology of female spotted seatrout, Cynoscion nebulosus, in the Gulf of Mexico: differences among estuaries? Environ Biol Fishes 63:405-415

*Bazzelli CP, Luettich RA Jr, Powers SP, Peterson $\mathrm{CH}_{\text {, }}$ McNinch JE, Pinckney JL, Paerl HW (2002) Estimating the spatial extent of bottom-water hypoxia and habitat degradation in a shallow estuary. Mar Ecol Prog Ser 230: 103-112

Cain RL, Dean JM (1976) Annual occurrence abundance and diversity of fish in a South Carolina intertidal creek. Mar Biol 36:369-379

* Connaughton MA, Taylor MH (1995) Seasonal and daily cycles in sound production associated with spawning in the weakfish, Cynoscion regalis. Environ Biol Fishes 42: 233-240

Connaughton MA, Taylor MH (1996) Drumming, courtship, and spawning behavior in captive weakfish, Cynoscion regalis. Copeia 1996:195-199

Connaughton MA, Taylor MH, Fine ML (2000) Effects of fish size and temperature on weakfish disturbance calls: implications for the mechanism of sound generation. J Exp Biol 203:1503-1512

Crick HQP, Sparks TH (1999) Climate change related to egg-laying trends. Nature 399:423

* Crick HQP, Dudley C, Glue DE, Thomson DL (1997) UK birds are laying eggs earlier. Nature 388:526

*Dawson A (2015) Annual gonadal cycles in birds: modeling the effects of photoperiod on seasonal changes in GnRH-1 secretion. Front Neuroendocrinol 37:52-64

* de Oliveira AG, Ventura TM, Ganchev TD, de Figueiredo JM, Jahn O, Marques MI, Schuchmann KL (2015) Bird acoustic activity detection based on morphological filtering of the spectrogram. Appl Acoust 98:34-42

* Dobrin MB (1947) Measurements of underwater noise produced by marine life. Science 105:19-23

* Dunn PO, Winkler DW (1999) Climate change has affected the breeding date of tree swallows throughout North America. Proc R Soc B 266:2487-2490

* Dylla M, Hrnicek A, Rice C, Ramachandran R (2013) Detection of tones and their modification by noise in nonhuman primates. J Assoc Res Otolaryngol 14:547-560

Edwards M, Richardson AJ (2004) Impact of climate change on marine pelagic phenology and trophic mismatch. Nature 430:881-884

* Eggleston DB, Lipcius RR, Marshall LS Jr, Ratchford SG (1998) Spatiotemporal variation in postlarval recruitment of the Caribbean spiny lobster in the central Bahamas: lunar and seasonal periodicity, spatial coherence, and wind forcing. Mar Ecol Prog Ser 174:33-49

Fine ML (1978) Seasonal and geographical variation of the mating call of the oyster toadfish Opsanus tau L. Oecologia 36:45-57

*Fine ML, Thorson RF (2008) Use of passive acoustics for assessing behavioral interactions in individual toadfish. Trans Am Fish Soc 137:627-637

Fine ML, Winn HE, Joest L, Perkins PJ (1977) Temporal aspects of calling behavior in oyster toadfish, Opsanus tau. Fish Bull 75:871-874

Fine ML, Economos D, Radtke R, McClung JR (1984) Ontogeny and sexual dimorphism of the sonic motor nucleus in the oyster toadfish. J Comp Neurol 225: 105-110

Fish MP, Mowbray WH (1970) Sounds of the Western North 
Atlantic fishes - a reference file of biological underwater sounds. The John Hopkins Press, Baltimore, MD

*Ganchev TD, Jahn O, Marques MI, de Figueiredo JM, Schuchmann KL (2015) Automated acoustic detection of Vanellus chilensis lampronotus. Expert Syst Appl 42: 6098-6111

Gannon DP, Taylor CM (2007) Acoustic behavior of Atlantic croaker, Micropogonias undulatus (Sciaenidae). Copeia 2007:193-204

Ghasemi A, Zahediasl S (2012) Normality tests for statistical analysis: a guide for non-statisticians. Int $\mathrm{J}$ Endocrinol Metab 10:486-489

Gilmore RG Jr (1994) Environmental parameters associated with spawning, larval dispersal, and early life history of the spotted seatrout Cynoscion nebulosus (Cuvier). Report to Marine Research Institute, Florida Department of Environmental Protection, St. Petersburg, FL

Gilmore RG Jr (2003) Sound production and communication in the spotted seatrout. In: Bortone SA (ed) Biology of the spotted seatrout. CRC Press, Boca Raton, FL, p 99-133

Goffredi SK, Jones WJ, Scholin CA, Marin R, Vrijenhoek RC (2006) Molecular detection of marine invertebrate larvae. Mar Biotechnol 8:149-160

Gray GA, Winn HE (1961) Reproductive ecology and sound production of the toadfish, Opsanus tau. Ecology 42: 274-282

* Greenfield MD, Esquer-Garrigos Y, Streiff R, Party V (2016) Animal choruses emerge from receiver psychology. Sci Rep 6:34369

Gudger EW (1910) Habits and life history of the toadfish (Opsanus tau). Bull US Bur Fish 28:1071-1109

*Guest WC, Lasswell JL (1978) A note on courtship behavior and sound production of red drum. Copeia 1978:337-338

Hartbauer M, Kratzer S, Steiner K, Römer H (2005) Mechanisms for synchrony and alternation in song interactions of the bushcricket Mecopoda elongata (Tettigoniidae: Orthoptera). J Comp Physiol A Neuroethol Sens Neural Behav Physiol 191:175-188

Helble TA, Ierley GR, D'Spain GL, Roch MA, Hildebrand JA (2012) A generalized power-law detection algorithm for humpback whale vocalizations. J Acoust Soc Am 131: 2682-2699

Hoegh-Guldberg O, Bruno JF (2010) The impact of climate change on the world's marine ecosystems. Science 328 : 1523-1528

Holt JG, Godbout R, Arnold CR (1981) Effects of temperature and salinity on egg hatching and larval survival of red drum Sciaenops ocellata. Fish Bull 79:569-573

Holt JG, Holt SA, Arnold CR (1985) Diel periodicity of spawning in sciaenids. Mar Ecol Prog Ser 27:1-7

Johnson DR, Funicelli NA (1991) Spawning of the red drum in Mosquito Lagoon, East-Central Florida. Estuaries 14: 74-79

Kandia V, Stylianou Y (2006) Detection of sperm whale clicks based on the Teager-Kaiser energy operator. Appl Acoust 67:1144-1163

Kim HY (2013) Statistical notes for clinical researchers: assessing normal distribution using skewness and kurtosis. Restor Dent Endod 38:52-54

* Locascio JV, Mann DA (2008) Diel periodicity of fish sound production in Charlotte Harbor, Florida. Trans Am Fish Soc 137:606-615

Locascio JV, Mann DA (2011) Diel and seasonal timing of sound production by black drum (Pogonias cromis). Fish Bull 109:327-338
Loman J (2016) Breeding phenology in Rana temporaria. Local variation is due to pond temperature and population size. Ecol Evol 6:6202-6209

KLowerre-Barbieri SK, Barbieri LR, Flanders JR, Woodward AG, Cotton CF, Knowlton MK (2008) Use of passive acoustics to determine red drum spawning in Georgia Waters. Trans Am Fish Soc 137:562-575

*uczkovich JJ, Sprague MW, Johnson SE, Pullinger RC (1999) Delimiting spawning areas of weakfish, Cynoscion regalis (Family Sciaenidae) in Pamlico Sound, North Carolina using passive hydroacoustic surveys. Bioacoustics 10:143-160

*Luczkovich JJ, Pullinger RC, Johnson SE, Sprague MW (2008) Identifying sciaenid critical spawning habitats by the use of passive acoustics. Trans Am Fish Soc 137: 576-605

* Mann DA, Lobel PS (1995) Passive acoustic detection of sounds produced by the damselfish, Dascyllus albisella (Pomacentridae). Bioacoustics 6:199-213

* Mann D, Locascio J, Schärer M, Nemeth M, Appeldoorn R (2010) Sound production by red hind Epinephelus guttatus in spatially segregated spawning aggregations. Aquat Biol 10:149-154

Maruska KP, Mensinger AF (2009) Acoustic characteristics and variations in grunt vocalizations in the oyster toadfish Opsanus tau. Environ Biol Fishes 84:325-337

*McMichael RH, Peters KM (1989) Early life-history of spotted seatrout, Cynoscion nebulosus (Pisces: Sciaenidae), in Tampa Bay, Florida. Estuaries 12:98-110

* Merchant ND, Fristrup KM, Johnson MP, Tyack PL, Witt MJ, Blondel P, Parks SE (2015) Measuring acoustic habitats. Methods Ecol Evol 6:257-265

*Miglarese JV, McMillan CW, Shealy MH (1982) Seasonal abundance of Atlantic croaker (Micropogonias undulatus) in relation to bottom salinity and temperature in South Carolina estuaries. Estuaries 5:216-223

Mok HK, Gilmore RG (1983) Analysis of sound production in estuarine aggregations of Pogonias cromis, Bairdiella chrysoura, and Cynoscion nebulosus (Sciaenidae). Bull Inst Zool Acad Sin 22:157-186

*Montie EW, Vega S, Powell M (2015) Seasonal and spatial patterns of fish sound production in the May River, South Carolina. Trans Am Fish Soc 144:705-716

Montie EW, Kehrer C, Yost J, Brenkert K, O'Donnell T, Denson MR (2016) Long-term monitoring of captive red drum Sciaenops ocellatus reveals that calling incidence and structure correlate with egg deposition. J Fish Biol 88: 1776-1795

Montie EW, Hoover M, Kehrer C, Yost J, Brenkert K, O'Donnell T, Denson MR (2017) Acoustic monitoring indicates a correlation between calling and spawning in captive spotted seatrout (Cynoscion nebulosus). PeerJ 5:e2944, doi:10.7717/peerj.2944

Moore SW, Lewis ER, Narins PM, Lopez PT (1989) The calltiming algorithm of the white-lipped frog, Leptodactylus albilabris. J Comp Physiol A Neuroethol Sens Neural Behav Physiol 164:309-319

*Mortensen RA, Arnott SA, Jones WJ, Greenfield DI (2015) Development of a sandwich hybridization assay for the identification and quantification of red drum (Sciaenops ocellatus) eggs: a novel tool for fishery research and management. Can J Fish Aquat Sci 72:915-925

Murphy MD, Taylor RG (1990) Reproduction, growth, and mortality of red drum Sciaenops ocellatus in Florida waters. Fish Bull 88:531-542 
Nieland DL, Wilson CA (1993) Reproductive biology and annual variation of reproductive variables of black drum in the northern Gulf of Mexico. Trans Am Fish Soc 122: 318-327

Nieland DL, Thomas RG, Wilson CA (2002) Age, growth and reproduction of spotted seatrout in Barataria Bay, Louisiana. Trans Am Fish Soc 131:245-259

Nityananda V, Balakrishnan R (2009) Modeling the role of competition and cooperation in the evolution of katydid acoustic synchrony. Behav Ecol 20:484-489

Overstreet RM (1983) Aspects of the biology of the spotted seatrout, Cynoscion nebulosus. Gulf Res Rep(Suppl 1): $1-43$

Pace F, White P, Adam O (2012) Hidden Markov modeling for humpback whale (Megaptera novaeangliae) call classification. Proc Meet Acoust 17:070046

* Parsons S (2001) Identification of New Zealand bats (Chalinolobus tuberculatus and Mystacina tuberculata) in flight from analysis of echolocation calls by artificial neural networks. J Zool (Lond) 253:447-456

Paul MJ, Zucker I, Schwartz WJ (2008) Tracking the seasons: the internal calendars of vertebrates. Philos Trans R Soc Lond B Biol Sci 363:341-361

Peterson MS, Comyns BH, Rakocinski CF, Fulling GL (2004) Defining the fundamental physiological niche of young estuarine fishes and its relationship to understanding distribution, vital metrics, and optimal nursery conditions. Environ Biol Fishes 71:143-149

Potamitis I, Ntalampiras S, Jahn O, Riede K (2014) Automatic bird sound detection in long real-field recordings: applications and tools. Appl Acoust 80:1-9

Ramcharitar J, Gannon DP, Popper AN (2006) Bioacoustics of fishes of the family Sciaenidae (croakers and drums). Trans Am Fish Soc 135:1409-1431

Rice AN, Morano JL, Hodge KB, Muirhead CA (2016) Spatial and temporal patterns of toad-fish and black drum chorusing activity in the South Atlantic Bight. Environ Biol Fishes 99:705-716

Riekerk GHM, Tyree SJ, Roumillat WA (1997) Spawning times and locations of spotted seatrout in the Charleston Harbor Estuarine System from acoustic surveys. Final report to Charleston Harbor Project Bureau of Ocean and Coastal Resources Management, South Carolina Department of Health and Environmental Control, Charleston, SC

Ross JL, Stevens TM, Vaughan DS (1995) Age, growth, mortality, and reproductive biology of red drums in North Carolina waters. Trans Am Fish Soc 124:37-54

Roumillat WA, Brouwer MC (2004) Reproductive dynamics of female spotted seatrout (Cynoscion nebulosus) in South Carolina. Fish Bull 102:473-487

Rountree RA, Gilmore RG, Goudey CA, Hawkins AD, Luczkovich JJ, Mann DA (2006) Listening to fish-applications of passive acoustics to fisheries science. Fisheries 31:433-446

Editorial responsibility: Elliott Hazen, Pacific Grove, California, USA
Saucier MH, Baltz DM (1993) Spawning site selection by spotted seatrout, Cynoscion nebulosus, and black drum, Pogonias cromis, in Louisiana. Environ Biol Fishes 36: 257-272

Sprague MW (2000) The single sonic muscle twitch model for the sound-production mechanism in the weakfish Cynoscion regalis. J Acoust Soc Am 108:2430-2437

Tavolga WN (1958) Underwater sounds produced by two species of toadfish Opsanus tau and Opsanus beta. Bull Mar Sci 8:278-284

Tavolga WN (1960) Sound production and underwater communication in fishes. In: Lanyon WE, Tavolga WN (eds) Animal sounds and communication. AIBS 7, Washington, DC, p 93-136

Tellechea JS, Norbis W, Olsson D, Fine ML (2011) Calls of the black drum (Pogonias cromis: Sciaenidae): geographical differences in sound production between northern and southern hemisphere populations. J Exp Zool A Ecol Genet Physiol 315:48-55

* Trifa VM, Kirschel ANG, Taylor CE, Vallejo EE (2008) Automated species recognition of antbirds in a Mexican rainforest using hidden Markov models. J Acoust Soc Am 123:2424-2431

Ubuka T, Bentley GE, Tsutsui K (2013) Neuroendocrine regulation of gonadotropin secretion in seasonally breeding birds. Front Neurosci 7:38

* Vasconcelos RO, Carriço R, Ramos A, Modesto T, Fonseca PJ, Amorim MCP (2012) Vocal behavior predicts reproductive success in a teleost fish. Behav Ecol 23:375-383

* Vieira M, Fonseca PJ, Amorim MCP, Teixeira CJ (2015) Call recognition and individual identification of fish vocalizations based on automatic speech recognition: an example with the Lusitanian toadfish. J Acoust Soc Am 138: 3941-3950

WWall CC, Simard P, Lembke C, Mann DA (2013) Large-scale passive acoustic monitoring of fish sound production on the West Florida Shelf. Mar Ecol Prog Ser 484:173-188

*Wall CC, Simard P, Lindemuth M, Lembke C and others (2014) Temporal and spatial mapping of red grouper Epinephelus morio sound production. J Fish Biol 85: 1470-1488

WWalters S, Lowerre-Barbieri S, Bickford J, Mann DA (2009) Using a passive acoustic survey to identify spotted seatrout spawning sites and associated habitat in Tampa Bay, Florida. Trans Am Fish Soc 138:88-98

*Walther G, Post E, Convey P, Menzel A and others (2002) Ecological responses to recent climate change. Nature 416:389-395

Winn HE (1964) The biological significance of fish sounds. In: Tavolga WN (ed) Marine bio-acoustics. Pergamon, New York, NY, p 213-231

Zeppelzauer M, Hensman S, Stoeger AS (2015) Towards an automated acoustic detection system for free-ranging elephants. Bioacoustics 24:13-29

Submitted: March 17, 2017; Accepted: September 1, 2017 Proofs received from author(s): October 3, 2017 